\title{
5 Chemical modification of nanocellulose
}

Extensive studies have been conducted on the utilization of cellulose nanocrystals, microfibrillated cellulose and bacterial cellulose as reinforcements in polymer nanocomposites. Efficiency of nanofiller dispersion in the matrix and adequacy of nanofiller-matrix interfacial interactions are widely known to critically affect material physical and mechanical properties. Because of its inherent hydrophilicity, it is difficult to achieve a good dispersion level of nanocellulose reinforcements in water-insoluble or non-water dispersible polymer matrices. This limitation stems primarily from the high affinity of nanocellulose for water and its inability to disperse readily in organic solvents. Cellulosic nanoparticles are characterized by hydrogen bonding-induced aggregation which is magnified because of their nanosized and fibrillar structures. To prevent self-aggregation (sometimes referred to as hornification) and promote efficient dispersion in non-aqueous media, the surface of cellulosic nanoparticles can be modified with hydrophobic compounds using covalent and non-covalent coupling techniques. A wide variety of chemical modification techniques, including coupling hydrophobic small molecules, grafting polymers and oligomers, and adsorbing hydrophobic compounds to surface hydroxyl groups of cellulosic nanoparticles, can be employed. Besides the problem of dispersibility with polymeric matrices, improved nanofiller-matrix interaction is expected to enhance the stress transfer from the matrix to the dispersed phase and then improve the loadbearing capability of the material. Moreover, the surface of the nanoparticles can be tailored to impart specific functionality to nanocellulose.

\subsection{Reactivity of cellulose}

According to its molecular structure, cellulose is an active chemical because of the presence of three hydroxyl groups in each anhydroglucose unit. These hydroxyl groups are therefore mainly responsible for the reactions of cellulose. As a carbohydrate, the chemistry of cellulose is primarily the chemistry of alcohols and it forms many of the common derivatives of alcohols, such as esters, ethers, etc. However, despite the fact that cellulose has a chemical similarity with sugars bearing three hydroxyl groups its reactivity should not be simply regarded as that of a trihydric alcohol. Indeed, native cellulose is a high molecular weight polymeric substance. Moreover, if the soluble form of cellulose is not considered, i.e. if the solid cellulosic substrate is suspended in a non-swelling liquid reaction medium, the reactions of cellulose occur under heterogeneous conditions.

Assuming the numbering system shown in Figure 5.1 for carbon atoms in anhydroglucose unit of cellulose, the hydroxyl group at the 6 position acts as a primary alcohol whereas the hydroxyl groups in the 2 and 3 positions behave as secondary alcohols. Indeed, it can be seen from Figure 5.1 that the carbon atom which carries 
the hydroxyl group in the 6 position is only attached to one alkyl group, while the carbons with the hydroxyl groups in the 2 and 3 positions are joined directly to two alkyl groups. Under heterogeneous conditions, the reactivity of these three hydroxyl groups can be affected by their inherent chemical reactivity, by steric effects produced by the reacting agent and by steric effects derived from the supramolecular structure of cellulose (Wakelyn, 1998). The relative reactivity has been established from esterification studies. It has been reported that the hydroxyl group at the 6 position can react ten times faster than the other $\mathrm{OH}$ groups (Hebeish and Guthrie, 1981). This high reactivity is generally ascribed to its isomerization. The reactivity of the hydroxyl group in the 2 position has, in the meantime, been found to be twice that of one of the hydroxyl group at the 3 position.

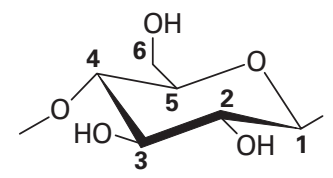

Fig. 5.1: The numbering system for carbon atoms in anhydroglucose unit of cellulose.

The hydroxyl groups of cellulose can be partially or fully reacted with various chemicals to provide derivatives with useful properties. These derivatives form the basis for much of the industrial technology of cellulose in use today. Because of the strong hydrogen bonds that occur between cellulose chains, cellulose does not melt or dissolve in common solvents. Thus, it is difficult to convert the short fibers from wood pulp into the continuous filaments needed for artificial silk, an early goal of cellulose chemistry. Several different cellulose derivatives were examined as early routes to artificial silk, but only two, the acetate and xanthate esters, are of commercial importance for fibers today.

An important parameter to characterize the extent or efficiency of reaction of cellulose is the degree of substitution (DS). It indicates the average number of hydroxyl groups of anhydroglucose moiety that are substituted after reaction. The DS value ranges between 0 and 3 and the maximum value of 3 indicates that all three hydroxyl groups are substituted. For composite applications, a non-swelling reaction medium should be used so that the reaction is restricted to the surface of the fiber/nanoparticle keeping its integrity. Therefore, rather than expressing the grafting efficiency referring to the number of grafted moieties per anhydroglucose unit regardless of their localization in the fiber/nanoparticle, it is preferable to refer to the fraction of substituted hydroxyl groups among those that are able to react (the $\mathrm{OH}$ groups at the surface).

The fraction of accessible hydroxyl groups is not easy to determine but can be roughly estimated from the specific surface area of the fiber/nanoparticle. For micro- 
scopic cellulosic fibers, it was shown that only $2 \%$ of hydroxyl groups are accessible at the surface for chemical modification (Trejo-O'Reilly et al., 1997). This calculation was based on the morphological characteristics of the fibers and taking into account that swelling was negligible in such non-swelling solvents. The determination of the specific surface area and then accessibility and reactivity of MFC and cellulose nanocrystals is more difficult to access by classical techniques because drying induces aggregation phenomenon of the nanoparticles leading to an underestimated value of the specific surface area as reported in Chapters 2 and 3. Therefore, geometrical considerations obtained from microscopic observations are generally used (Siqueira et al., 2009). The number of cellulose chains close packed to form MFC or nanocrystals can then be estimated from crystallographic data for native cellulose (Gardner and Blackwell, 1974). For instance, it was shown that cellulose nanocrystals extracted from wheat straw (Helbert et al., 1996) or sisal (Siqueira et al., 2009) both with a width around $5 \mathrm{~nm}$ consist of close packing of about 40 chains. For sisal MFC with a width of $52 \mathrm{~nm}$, the number of close packed cellulose chains was estimated around 4,000 (Siqueira et al., 2009). In the case of tunicin nanocrystals with a square section equal to $15 \cdot 15 \mathrm{~nm}^{2}$, it was estimated that 344 unit cells and 688 chains were packed, since there are two chains per unit cell (Favier et al., 1997). Assuming a square cross section for cellulosic nanoparticles, the number and fraction of cellulosic chains laying on the surface can be estimated. However, even for these surface cellulosic chains, not all hydroxyl groups are accessible, since some are oriented toward the inner of the nanoparticle. It was assumed that only one-third and one-half of hydroxyl groups from cellulosic chains at the surface of nanocrystals and MFC, respectively, can react (Siqueira et al., 2009). Indeed, due to higher crystallinity of nanocrystals, and knowing that primary hydroxyl on C6 is the most reactive, it was assumed that the fraction of hydroxyl groups available on the surface was $1 / 3$ for nanocrystals and $1 / 2$ for MFC. Therefore, the DS experimentally determined should be divided by the fraction of cellulose chain at the surface of the nanoparticles and by a factor 3 for nanocrystals and by a factor 2 for MFC, to refer to the fraction of substituted hydroxyl groups that are able to react (the $\mathrm{OH}$ groups at the surface).

A higher reactivity of cellulosic fibers and DS with a more homogeneous substituent distribution can be obtained using different activation treatments (Roy et al., 2009). It includes (i) opening surface cannulae, internal pores and cavities, and interfibrillar interstices, (ii) disrupting fibrillar aggregations, in order to make available additional surface, (iii) disturbing the crystalline order, and (iv) altering the crystal modification, thus changing the hydrogen bonding scheme and the relative availability of reactive hydroxyl groups (Krassig, 1985; Krassig, 1993). The most frequently used activation method consists in swelling cellulose in solutions of acids, bases, salts and some organic solvents (Roy et al., 2009). 


\subsection{Surface chemistry of cellulose nanoparticles}

Because of their nanoscale dimensions, cellulose nanoparticles display a high surface area generally of the order of few $100 \mathrm{~m}^{2} \cdot \mathrm{g}^{-1}$ and their ample surface hydroxyl groups $\left(2-3 \mathrm{mmol} \cdot \mathrm{g}^{-1}\right)$ enable targeted surface modification to introduce virtually any desired surface functionality (Eyley and Thielemans, 2011). However, the surface chemistry of cellulose nanoparticles is primary governed by the extraction procedure used to prepare these nanoparticles from the native cellulosic substrate (Moon et al., 2011). Figure 5.2 shows the surface chemistries provided by the most common extraction methods.

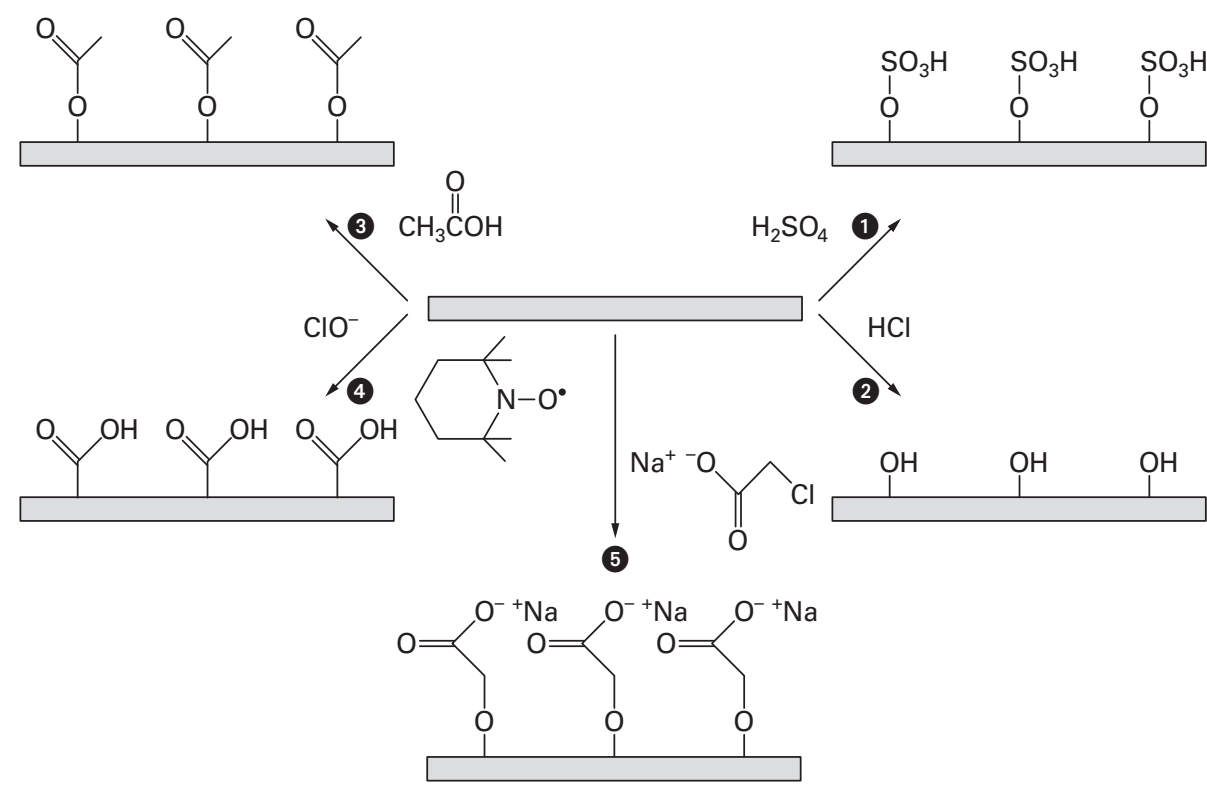

Fig. 5.2: Distinctive surface chemistries provided by the most common extraction methods of cellulose nanoparticles: sulfuric acid hydrolysis provides sulfate ester groups (route $\mathbf{0}$ ), hydrochloric acid hydrolysis provides hydroxyl groups (route (2), acetic acid hydrolysis provides acetyl groups (route $\mathbf{3}$ ), TEMPO mediated hypochlorite treatment (route $\mathbf{(})$ and carboxymethylation (route $\mathbf{5}$ ) provide carboxylic acid groups.

Cellulose nanocrystals are generally prepared by sulfuric acid hydrolysis inducing the formation of sulfate ester groups on the surface of the nanoparticles. These charged moieties, whose density increases with the severity (acid concentration, time, temperature) of the treatment, are responsible for the high stability of the $\mathrm{H}_{2} \mathrm{SO}_{4}$-prepared nanocrystal aqueous suspensions. Hydrolysis of cellulose with hydrochloric acid preserves the hydroxyl groups of the native fibers but leads to less stable suspensions. More marginally, acetic acid mixed with hydrochloric acid was used to prepare func- 
tionalized cellulose nanocrystals in a single step (Braun and Dorgan, 2009). Fischer esterification of hydroxyl groups induced simultaneously the hydrolysis of amorphous cellulose chains and isolation of functionalized nanoparticles with an acetylated surface.

MFC is generally prepared with purely mechanical methods. Hydroxylated surfaces similar to native cellulose are therefore obtained. However, as reported in Chapter 2, several strategies have been proposed to decrease the energy consumption for fibrillation. One of these methods, increasingly used, is TEMPO (2,2,6,6-tetramethylpiperidine-1-oxyl radical)-mediated oxidation of cellulose coupled with mild mechanical disintegration treatment (Isogai et al., 2011). The primary oxidant, such as hypochlorite, selectively oxidizes primary alcohol groups of cellulose. This oxidation pretreatment allows leaving carboxylic acid groups at the surface of fibrillated cellulose. Carboxymethylation was also used as pretreatment prior to mechanical defibrillation to decrease the energy associated with the process (Wågberg et al., 2008). The ensuing carboxymethylated MFC material also bear carboxyl groups. Water-redispersible MFC in powder form was also prepared from refined, bleached beech pulp by carboxymethylation and mechanical disintegration (Eyholzer et al., 2010). The sequence of the treatments was changed and it was observed that samples that were first carboxymethylated formed a more transparent suspension in water and showed a more homogeneous network.

It has been shown that when cotton cellulose nanocrystals were chemically modified directly after acid hydrolysis followed by dialysis, reproducibility between batches was problematic (Labet and Thielemans, 2011). It was suspected to result from a variable surface composition. Given the inherent purity of acid hydrolysis extracted nanoparticles, this issue was believed to be due to the presence of adsorbed species at the surface of the nanocrystals blocking reactive sites. Soxhlet extraction with different solvents of cellulose nanocrystals from several batches was performed and extracted impurities were analyzed by nuclear magnetic resonance $\left({ }^{1} \mathrm{H}\right.$ and ${ }^{13} \mathrm{C}$ NMR) and mass spectrometries. Dichloromethane, ethanol, ethyl acetate, heptane, methanol and isopropanol were used as solvents and it was shown that a variety of adsorbed species can be removed by Soxhlet extraction. It was concluded from this study that a $24 \mathrm{~h}$ ethanol extraction is required and sufficient for the purification of cellulose nanocrystals and this extraction was recommended to be performed before any surface modification attempt, from a simple surface esterification to grafting polymers from the surface.

The hydroxyl groups from the cellulose nanoparticle surface need to be fully accessible for chemical reactions. This means that their surface should remain clean and that aggregation of the nanoparticles should be avoided. A medium-driven surface adaptation phenomenon of cellulose to minimize its surface free energy was evidenced using MFC (Johansson et al., 2011). Changes of surface properties, nanoscale structure and surface accessibility subsequent to solvent exchanges or drying in air were investigated. In this study, aqueous MFC suspensions were solvent 
exchanged to acetone and then to either toluene or dimethyl acetamide (DMAc). Due to the amphiphilic character of both DMAc and cellulose, MFC remained well dispersed in DMAc while extensive aggregation of the nanoparticles and loss of both the reactivity and the nanostructure occurred when solvent exchanging to non-polar toluene. Passivation of the cellulose surface when exposed to non-hydrophilic media was evidenced. Actually, in water, an excellent hydrogen bonding solvent, the surface hydroxyl groups stay clean and accessible whereas upon drying, MFC aggregates and accumulates air-borne contaminants to adapt to the non-polar medium. These contaminants were evidenced through the $\mathrm{C}-\mathrm{C}$ carbon peak in X-ray photoelectron spectroscopy (XPS) data and contact angle measurements. As a result, it was shown that silylation conducted in cellulose compatible DMAc gave a significantly higher DS compared to the silylation conducted in toluene.

\subsection{Non-covalent surface chemical modification of cellulose nanoparticles}

The surface of cellulose nanoparticles can be modified and tuned by physical interactions or adsorption of molecules or macromolecules onto their surface. This method appears much simpler than chemical grafting since no chemical reaction is involved.

\subsubsection{Adsorption of surfactant}

The surface of cellulose nanoparticles can be tuned for instance by using surfactants as stabilizing agents. Surfactants are usually amphiphilic organic compounds, i.e. compounds containing both hydrophobic groups (so-called tails) and hydrophilic groups (so-called heads). Therefore, a surfactant molecule contains both a water insoluble (or oil soluble) component and a water soluble component. The hydrophilic end of the surfactant molecule may adsorb on the surface of cellulose nanoparticles whereas the hydrophobic end may extend out providing a non-polar surface and lowering the surface tension of the nanoparticle. The ensuing surfactant-coated nanoparticles can be easily dispersed in non-polar organic media.

An anionic surfactant consisting of acid phosphate ester of ethoxylated nonylphenol has been applied to cotton and tunicin nanocrystals (Heux et al., 2000), as well as nanocrystals extracted from MCC (Kvien et al., 2005; Bondeson and Oksman, 2007; Fortunati et al., 2012) and cotton linters (Elazzouzi-Hafraoui et al., 2009). Owing to the high specific surface area of these nanoparticles, the ratio of adsorbed surfactant to cellulose was found to be 0.7 for cotton and 1.5 for tunicin. Small angle neutron scattering (SANS) experiments have shown that a thin layer around $15 \AA$ was formed at the surface of the nanoparticles by the surfactant molecules (Bonini et al., 2002). A 
similar value was observed from UV-visible spectrophotometry for cotton linter nanocrystals (Elazzouzi-Hafraoui et al., 2009).

Nonionic sorbitan monostearate surfactant was also used to disperse cellulose nanocrystals in polystyrene-based electrospun composite fibers (Kim et al., 2009; Rojas et al., 2009). Model cellulose surfaces based on cellulose nanocrystals extracted from bleached cotton, sisal and ramie fibers were prepared by the Langmuir-Schaeffer technique (Habibi et al., 2010). A cationic surfactant, namely dioctadecyldimethylammonium bromide, was used to prepare cellulose-surfactant complexes that allowed transfer of the nanocrystal from the air/liquid interface in the aqueous suspension to hydrophobic solid substrates. Strong interactions between negatively $\mathrm{H}_{2} \mathrm{SO}_{4}$-prepared cellulose nanocrystals and the cationic surfactant by way of electrostatic interactions were expected.

Cellulose films prepared from carboxymethylated MFC were modified by coating with various amounts of a fluorosurfactant, namely perfluorooctadecanoic acid $\left(\mathrm{C}_{17} \mathrm{~F}_{35} \mathrm{COOH}\right)$ (Aulin et al., 2008). When MFC was prepared using a TEMPO-mediated oxidation pretreatment, films obtained from these nanofibrils had anionic sites on their surface. Therefore, their surface can be easily modified with a cationic surfactant applied directly on the film surface. N-hexadecyl trimethylammonium bromide (cetyltrimethylammonium bromide CTAB) dissolved in water was deposited on the surface of MFC films (Syverud et al., 2011). The adsorbed layer of CTAB was found to increase the hydrophobicity of the film without affecting its mechanical properties significantly. Because of the antiseptic properties of CTAB, new applications can be considered. CTAB, as well as didodecyl- (DDDAB) and dihexadecyl ammonium bromide (DHDAB) were used to control the water repellency of cellulose nanofibrils (Xhanari et al., 2011). In this study, the surfactant was directly added to MFC in water suspension. Because DDDAB and DHDAB are insoluble in water at room temperature, it was necessary to solubilize them by heating at $75^{\circ} \mathrm{C}$. Small aggregates (admicelles) of surfactant were shown to form on the surface of the nanofibrils, well below critical micelle concentrations.

\subsubsection{Adsorption of macromolecules}

The basic principle is similar to the one provided by a surfactant. This means that to be adsorbed on the surface of cellulose nanoparticles, the macromolecule should bear both hydrophilic and hydrophobic moieties.

Surface modification of cotton cellulose nanocrystals using a xyloglucan oligosaccharide-based triblock copolymer was reported (Zhou et al., 2009). By mimicking lignin-carbohydrate copolymers, a xyloglucan oligosaccharide-poly(ethylene glycol) (PEG)-polystyrene (PS) triblock copolymer was synthesized by coupling prefabricated linear blocks and adsorbed onto the surface of nanoparticles. PEG was used as a compatible block between the carbohydrate and hydrophobic PS blocks. A solution of the 
copolymer in dimethylformamide (DMF) was mixed with the aqueous suspension of nanocrystals and the mixture was subsequently freeze-dried. Ensuing nanocrystals showed good dispersion abilities in non-polar liquids.

High molecular weight polyoxyethylene (PEO) dissolved in water was adsorbed on the surface of cotton nanocrystals (Ben Azouz et al., 2012). Adsorption was suspected from the rheological behavior of the PEO solution whose viscosity decreased when the nanoparticles were added. When saturation of the nanocrystal surface was reached, the viscosity of the suspension was found to increase. These PEO-coated cellulose nanocrystals were successfully extruded with hydrophobic polymer, enhancing both the dispersibility and thermal stability of the nanoparticles.

\subsection{Esterification, acetylation and acylation}

The hydrophobization of cellulose surface has often been achieved through the well-known aptitude of cellulose to undergo esterification reactions. The cellulose esterification process basically uses acid anhydrides or acyl chlorides as acetylating agents. Esterification is a reaction that introduces an ester functional group COO on the surface of cellulose nanoparticles by condensation of a carboxylic acid group $\mathrm{COOH}$ and alcohol group $\mathrm{OH}$. Acetylation is a reaction that introduces an acetyl functional group $\mathrm{COCH}_{3}$ on the surface of cellulose nanoparticles. It is the basic reaction involved in the preparation of the cellulose derivative, cellulose acetate, which is of commercial importance for the preparation of fibers and film base. Native cellulose can be gradually converted into cellulose acetate and cellulose triacetate upon the addition of acetic anhydride in the presence of a small amount of catalyst, such as sulfuric or perchloric acid. Commercially, the largest amount of cellulose acetate is produced by the so-called "acetic acid process". In this heterogeneous process, the cellulose is first swelled in acetic acid and then acetylated with acetic anhydride in the presence of sulfuric acid or perchloric acid as catalysts. Acetic acid is recovered as a by-product of the reaction as shown in Figure 5.3.

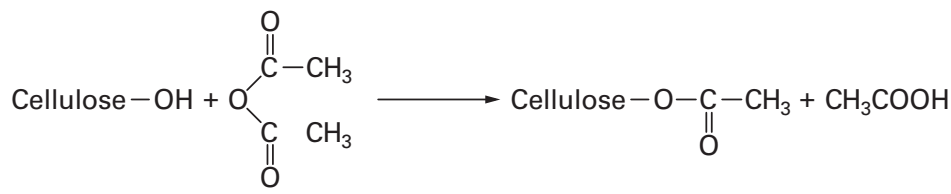

Fig. 5.3: Acetylation of cellulose with acetic anhydride.

This reaction has been conducted on different nanocellulosic substrates. Some of these studies are collected in Table 5.1. Several methods have been used to achieve acetylation and esterification of cellulose nanoparticles. Based on a non-swelling 


\begin{tabular}{|c|c|c|c|c|}
\hline $\begin{array}{l}\text { Source of } \\
\text { Cellulose }\end{array}$ & $\begin{array}{l}\text { Nano- } \\
\text { particle }\end{array}$ & Reagent & $\begin{array}{l}\text { Objective of the } \\
\text { Modification }\end{array}$ & Reference \\
\hline \multirow[t]{3}{*}{$\begin{array}{l}\text { Bacterial } \\
\text { Cellulose }\end{array}$} & - & Acetic anhydride & $\begin{array}{l}\text { Enhancement of } \\
\text { properties of acrylic } \\
\text { resin }\end{array}$ & $\begin{array}{l}\text { (Nogi et al., 2006; Ifuku et } \\
\text { al., 2007) }\end{array}$ \\
\hline & & Palmitoyl acid (gas phase) & Hydrophobization & (Berlioz et al., 2009) \\
\hline & & $\begin{array}{l}\text { Acetic, hexanoic and } \\
\text { dodecanoic acids }\end{array}$ & Hydrophobization & (Lee et al., 2011) \\
\hline $\begin{array}{l}\text { Bleached } \\
\text { Sulfite Wood } \\
\text { Pulp }\end{array}$ & MFC & Acetic anhydride & $\begin{array}{l}\text { Dispersion in } \\
\text { chloroform and } \\
\text { compatibilization } \\
\text { with PLA }\end{array}$ & (Tingaut et al., 2010) \\
\hline \multirow[t]{3}{*}{ Cotton Linters } & $\mathrm{CNC}$ & $\begin{array}{l}\text { Acetic acid and butyric } \\
\text { acid }\end{array}$ & $\begin{array}{l}\text { Dispersion in ethyl } \\
\text { acetate and toluene }\end{array}$ & $\begin{array}{l}\text { (Braun and Dorgan, 2009; } \\
\text { Sobkowicz et al., 2009) }\end{array}$ \\
\hline & & Vinyl acetate & Dispersion in THF & (Çetin et al., 2009) \\
\hline & & Acetic anhydride & $\begin{array}{l}\text { Dispersion in chlo- } \\
\text { roform }\end{array}$ & (Lin et al., 2011) \\
\hline $\begin{array}{l}\text { Kenaf Bast } \\
\text { Fibers }\end{array}$ & MFC & Acetic anhydride & $\begin{array}{l}\text { Dispersion in } \\
\text { acetone and ethanol }\end{array}$ & (Jonoobi et al., 2010) \\
\hline MCC & $\mathrm{CNC}$ & Acetic anhydride & $\begin{array}{l}\text { Redispersibility in } \\
\text { water }\end{array}$ & (Wang et al., 2007) \\
\hline $\begin{array}{l}\text { Norway } \\
\text { Spruce Kraft } \\
\text { Pulp }\end{array}$ & MFC & Acetic anhydride & $\begin{array}{l}\text { Hydrophobization } \\
\text { of films }\end{array}$ & (Rodionova et al., 2011) \\
\hline Ramie & $\mathrm{CNC}$ & $\begin{array}{l}\text { Hexanoyl chloride, } \\
\text { lauroyl chloride and } \\
\text { stearoyl chloride }\end{array}$ & $\begin{array}{l}\text { Extrusion with } \\
\text { LDPE }\end{array}$ & (de Menezes et al., 2009) \\
\hline \multirow[t]{3}{*}{ Tunicin } & & $\begin{array}{l}\text { Iso-octadecenyl succinic } \\
\text { anhydride and n-tetrade- } \\
\text { cenyl succinic anhydride }\end{array}$ & $\begin{array}{l}\text { Dispersion in sol- } \\
\text { vents of low polarity }\end{array}$ & (Yuan et al., 2006) \\
\hline & & $\begin{array}{l}\text { Acetic anhydride and } \\
\text { acetic acid }\end{array}$ & $\begin{array}{l}\text { Ultrastructural } \\
\text { aspect of acetyla- } \\
\text { tion }\end{array}$ & (Sassi and Chanzy, 1995) \\
\hline & & Palmitoyl acid (gas phase) & Hydrophobization & (Berlioz et al., 2009) \\
\hline Valonia & & $\begin{array}{l}\text { Acetic anhydride and } \\
\text { acetic acid }\end{array}$ & $\begin{array}{l}\text { Ultrastructural } \\
\text { aspect of acetyla- } \\
\text { tion }\end{array}$ & (Sassi and Chanzy, 1995) \\
\hline
\end{tabular}

Table 5.1: Acetylation of cellulosic nanoparticles. 
reaction mechanism, the reaction only occurred on the cellulose chains located at the surface of the nanoparticles. The limitation on the extent of acetylation lies in the susceptibility and accessibility of the surface.

The ultrastructural investigation of well-characterized tunicin and Valonia nanocrystals subjected to homogeneous and heterogeneous acetylation was reported (Sassi and Chanzy, 1995). TEM observations and diffraction contrast images of the nanoparticles at various stages of the reaction showed that the acetylation proceeded by a reduction of the diameters of the nanocrystals, while their lengths were reduced to a lower extent as shown by comparing Figures 5.4(a) and 5.4(b). It was supposed that the nanocrystals break down laterally but not longitudinally upon acetylation (peeling effect). A model of acetylation based on a non-swelling reaction mechanism that affects only the cellulosic chains located at the surface of the nanoparticle was proposed (Figure 5.4(c)). For homogeneous acetylation, the partially acetylated molecules were found to be sucked into the acetylating medium when sufficiently soluble whereas in heterogeneous conditions, the cellulose acetate remained insoluble and surrounded the crystalline core of unreacted cellulose.

Based on earlier studies carried out with chitin (Gopalan Nair et al., 2003) and starch (Angellier et al., 2005) nanocrystals, alkenyl succinic anhydride (ASA) was used to confer high hydrophobicity to cellulose nanocrystals (Yuan et al., 2006). In both former works, organic solvents were used to avoid hydrolysis of ASA. Acylation
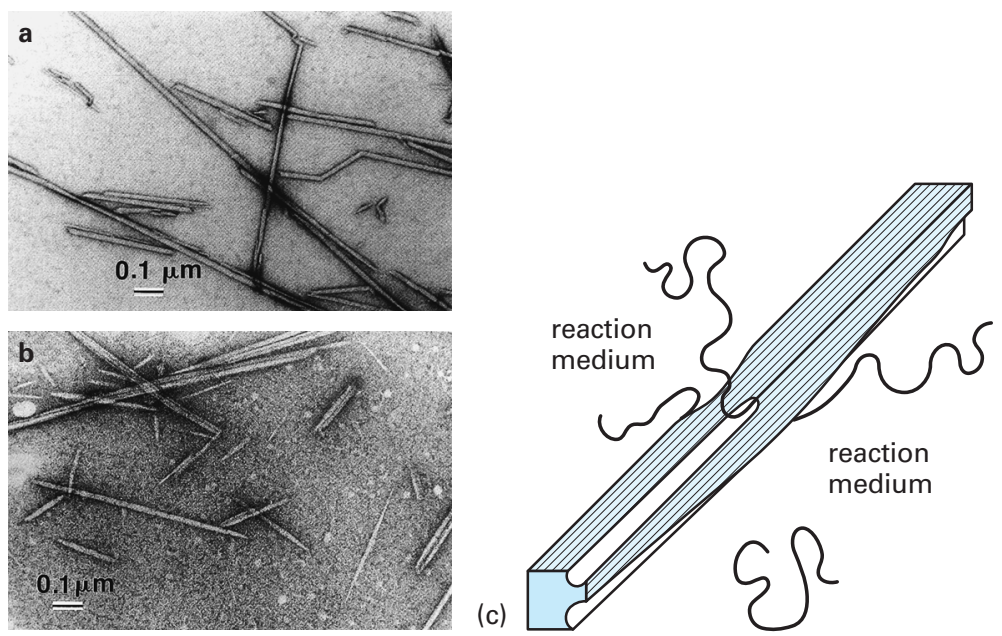

Fig. 5.4: Transmission electron micrographs from a dilute suspension of tunicin nanocrystals (a) before and (b) after partial acetylation (DS $=0.17$ ), and (c) schematic drawing describing the onset of the acetylation of a typical cellulose crystal. A chain that is sufficiently acetylated to become soluble has left the crystal. Three chains in the process of acetylation are partially lifted from the crystal. The crystal is indented by a series of grooves that correspond to the missing cellulose chains (Sassi and Chanzy, 1995). 
of chitin nanocrystals was achieved in a dioxane system with 4-(dimethylamino) pyridine as the catalyst and the reaction was carried out for 1 week at $70^{\circ} \mathrm{C}$ (Gopalan Nair et al., 2003). The toluene/ (dimethylammo)pyridine system was used to modify starch nanocrystals (Angellier et al., 2005). ASA is widely used as a sizing agent in papermaking, where it is applied to pulp fibers in aqueous systems. ASA aqueous emulsions were mixed with tunicin nanocrystal suspensions, freeze-dried and heated at $105^{\circ} \mathrm{C}$ to induce the esterification of hydroxyl groups of cellulose. From this environmentally-friendly procedure, highly hydrophobic nanocrystals were obtained with low reagent consumption and esterified nanoparticles were dispersed into mediumto low-polarity solvents, i.e. DMSO and 1,4-dioxane. Nanocrystals with different dispersibility could be obtained by controlling the heating time. Surface acetylation of cellulose nanocrystals (obtained from MCC) was undertaken by transesterification of vinyl acetate in the presence of potassium carbonate as catalyst (Çetin et al., 2009). By progressively increasing the reaction times, it was observed that the crystalline structure of the nanoparticles was destroyed. Improved stability of acetylated nanocrystals in tetrahydrofurane (THF) was reported with increased acetylation.

To avoid complex surface functionalization routes, the simultaneous hydrolysis and acetylation of cellulose nanocrystals in a single step has been reported (Braun and Dorgan, 2009). Using a mixture of hydrochloric acid ( $\mathrm{HCl})$ and organic acid (acetic and butyric were both demonstrated), amorphous cellulose chains were hydrolyzed and cellulose nanocrystals were functionalized by a Fischer esterification process of hydroxyl groups in a one-pot reaction methodology (Figure 5.5). It was shown that about half of the surface hydroxyl groups were esterified using this procedure. This approach is also quite versatile as the chain length of the covalently grafted surface group is easily controlled through the choice of organic acid employed in the reaction, the only restriction being that it has some miscibility with water. The presence of acetate and butyrate groups affected the hydrophilicity of cellulose nanocrytals making their aqueous suspensions unstable, but they possessed better dispersibility in ethyl acetate and toluene.

Esterification of ramie cellulose nanocrystals by reacting organic fatty acid chlorides with different lengths of the aliphatic chain (C6 to C18) under reflux was reported (de Menezes et al., 2009). The crystalline core of the nanoparticles was found to be unaffected while the grafting density was high enough to allow crystallization of grafted chains when using backbones of 18 carbon atoms. Crystallization of the grafted chains was evidenced from X-ray diffraction and differential scanning calorimetry (DSC) experiments. The DS was found to decrease with increasing carbon chain length of the organic acid used. Similar results were reported for bacterial cellulose (BC) modified using an esterification reaction with acetic acid, hexanoic acid or dodecanoic acid (Lee et al., 2011). Apart from the solution process, a gas-phase process using evaporation of large excess of palmitoyl chloride to achieve a surface to core esterification was investigated (Berlioz et al., 2009). The method was developed for freeze-dried tunicin nanocrystals and bacterial cellulose microfibrils dried 


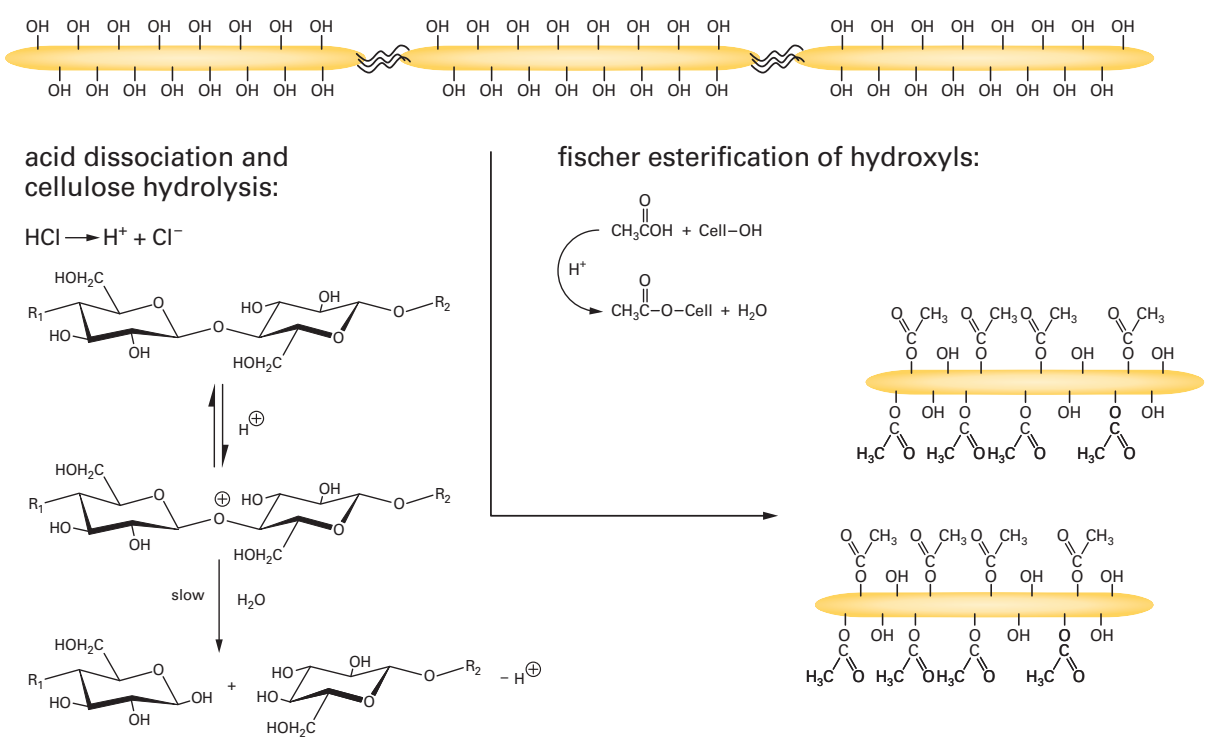

Fig. 5.5: Reaction scheme illustrating the simultaneous occurrence of cellulose hydrolysis and esterification of hydroxyl groups using a mixture of acetic and hydrochloric acid (Braun and Dorgan, 2009).

by the critical point method. This procedure can be extended to esterification of different fatty acid chlorides. The experimental conditions, nature and conditioning of cellulose were found to be important factors controlling the extent of esterification and morphology of the grafted nanoparticles. It was observed that the esterification proceeded from the surface of the cellulosic substrate to the crystalline core. For moderate DS, the surface was fully grafted whereas the cellulose core remained unmodified, and under certain conditions, an almost total esterification could be achieved, leading to highly substituted cellulose esters.

\subsection{Cationization}

Treatment with cations can be performed to render cellulose nanoparticles cationic by introducing positive charges on their surface. This strategy applied to cellulose fibers is largely used in the pulp and paper industry. A one-step method was reported to introduce positive charges on the surface of cellulose nanocrystals through the grafting of weak or strong ammonium-containing groups, such as epoxypropyltrimethylammonium chloride (EPTMAC) (Hasani et al., 2008). The surface cationization procedure was conducted via a nucleophilic addition of alkali-activated cellulose hydroxyl groups to the epoxy moiety of EPTMAC. Under mild alkaline cationization conditions the original morphology of the nanocrystals was preserved and their 
integrity was maintained. This functionalization process reversed the surface charge but the charge density was similar. However, functionalized nanocrystals made better monolayers on anionic mica when observed by AFM. Moreover, stable aqueous suspensions of modified nanocrystals showed unexpected thixotropic gelling properties. Shear birefringence was observed, but thixotropic gels inhibit the formation of chiral nematic liquid crystalline phase, because no liquid crystalline chiral nematic phase separation was detected.

\subsection{Silylation}

Silylation consists in the introduction of substituted silyl groups $\mathrm{R}_{3} \mathrm{Si}$ on the surface of cellulose nanoparticles. Many organofunctional silanes have been developed as coupling agents for glass-reinforced polymer composites. The general formula of an organosilane RR'R”SiX shows two classes of functionality. The X functional group is involved in the reaction with the cellulosic substrate (Figure 5.6). The bond between $\mathrm{X}$ and the silicon atom in coupling agents is therefore replaced by a bond between the cellulosic substrate and the silicon atom. $\mathrm{X}$ is a hydrolyzable group, typically alkoxy, acyloxy, amine, or chlorine. The most common alkoxy groups are methoxy and ethoxy, which give methanol and ethanol as by-products during coupling reactions. Chlorosilanes generate hydrogen chloride as a by-product during the coupling reactions.

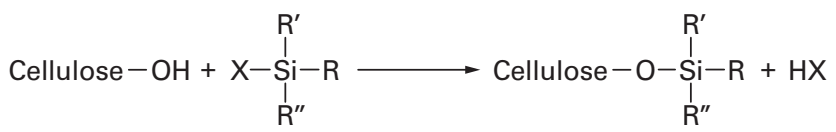

Fig. 5.6: Silylation of cellulose.

This reaction has been conducted on different nanocellulosic substrates. Some of these studies are collected in Table 5.2.

The first partial silylation of cellulose nanoparticles was conducted using tunicin nanocrystals and a series of alkyldimethylchlorosilanes, with alkyl moieties ranging from isopropyl to n-butyl, n-octyl and n-dodecyl (Goussé et al., 2002). It was shown that with a surface DS of the order of 0.6-1, the nanocrystals kept their morphological integrity, but due to their surface silylation, they became readily dispersible in solvents of low polarity such as THF. The resulting suspensions did not flocculate and appeared birefringent when viewed between cross polars. However, for surface DS higher than 1, the core of the nanocrystals also became silylated leading to the loss of their crystal character and it was no longer possible to obtain birefringent suspensions. Cotton nanocrystals functionalized by partial silylation through reaction with 


\begin{tabular}{|c|c|c|c|c|c|}
\hline $\begin{array}{l}\text { Source of } \\
\text { Cellulose }\end{array}$ & $\begin{array}{l}\text { Nano- } \\
\text { particle }\end{array}$ & Silane & DS & $\begin{array}{l}\text { Objective of the } \\
\text { Modification }\end{array}$ & Reference \\
\hline $\begin{array}{l}\text { Bacterial } \\
\text { Cellulose }\end{array}$ & $\mathrm{CNC}$ & $\begin{array}{l}\text { Hexamethyl } \\
\text { disilazane }\end{array}$ & 0.49 & $\begin{array}{l}\text { Dispersion in acetone } \\
\text { and compatibilization } \\
\text { with acetate butyrate }\end{array}$ & $\begin{array}{l}\text { (Grunert and Winter, } \\
\text { 2002a; 2002b) }\end{array}$ \\
\hline $\begin{array}{l}\text { Bleached } \\
\text { Birch Kraft } \\
\text { Pulp }\end{array}$ & MFC & & $0.03-0.9$ & $\begin{array}{l}\text { Evidence of } \\
\text { medium-driven } \\
\text { reactivity of cellulose }\end{array}$ & $\begin{array}{l}\text { (Johansson et al., } \\
\text { 2011) }\end{array}$ \\
\hline \multirow{3}{*}{$\begin{array}{l}\text { Bleached } \\
\text { Spruce } \\
\text { Sulfite } \\
\text { Cellulose }\end{array}$} & & \multirow[t]{2}{*}{$\begin{array}{l}\text { Chlorodimethyl } \\
\text { isopropylsilane }\end{array}$} & $0.6-1$ & Hydrophobization & $\begin{array}{l}\text { (Andresen et al., } \\
\text { 2006) }\end{array}$ \\
\hline & & & $0-1.1$ & $\begin{array}{l}\text { Stabilization of } \\
\text { emulsions }\end{array}$ & $\begin{array}{l}\text { (Andresen and } \\
\text { Stenius, 2007) }\end{array}$ \\
\hline & & $\begin{array}{l}\text { Octadecyldimethyl } \\
\text { (3-trimethoxysilyl- } \\
\text { propyl) ammonium } \\
\text { chloride }\end{array}$ & - & Antimicrobial activity & $\begin{array}{l}\text { (Andresen et al., } \\
\text { 2007) }\end{array}$ \\
\hline Cotton & $\mathrm{CNC}$ & $\begin{array}{l}\mathrm{N} \text {-dodecyldimethyl- } \\
\text { chlorosilane }\end{array}$ & - & $\begin{array}{l}\text { Dispersion in THF } \\
\text { and chloroform and } \\
\text { compatibilization } \\
\text { with PLA }\end{array}$ & (Pei et al., 2010) \\
\hline Kraft Pulp & MFC & $\begin{array}{l}\text { 3-aminopropyltri- } \\
\text { ethoxysilane and } \\
\text { 3-glycidoxypropyl- } \\
\text { trimethoxysilane }\end{array}$ & - & $\begin{array}{l}\text { Dispersion in acetone } \\
\text { and compatibilization } \\
\text { with epoxy }\end{array}$ & (Lu et al., 2008) \\
\hline Ramie & $\mathrm{CNC}$ & $\begin{array}{l}\text { Aminopropyltrietho- } \\
\text { xysilane, n-propyl- } \\
\text { trimethoxysilane, } \\
\text { methacryloxypro- } \\
\text { pyltrimethoxysilan, } \\
\text { acryloxypropyltrime- } \\
\text { thoxysilane }\end{array}$ & - & $\begin{array}{l}\text { Compatibilization } \\
\text { with PLA }\end{array}$ & $\begin{array}{l}\text { (Raquez et al., } \\
\text { 2012) }\end{array}$ \\
\hline $\begin{array}{l}\text { Sugar Beet } \\
\text { Pulp }\end{array}$ & MFC & $\begin{array}{l}\text { Isopropyl dimethyl- } \\
\text { chlorosilane }\end{array}$ & $0-0.36$ & $\begin{array}{l}\text { Dispersion in methyl } \\
\text { oleate }\end{array}$ & $\begin{array}{l}\text { (Goussé et al., } \\
\text { 2004) }\end{array}$ \\
\hline Tunicin & $\mathrm{CNC}$ & $\begin{array}{l}\text { Isopropyl, n-butyl, } \\
\text { n-octyl and n-dode- } \\
\text { cyldimethylchloro- } \\
\text { silane }\end{array}$ & $0-1$ & Dispersion in THF & $\begin{array}{l}\text { (Goussé et al., } \\
\text { 2002) }\end{array}$ \\
\hline
\end{tabular}

Table 5.2: Silylation of cellulosic nanoparticles. 
n-dodecyldimethylchlorosilane were homogeneously dispersed in PLA and found to increase the crystallization rate of the matrix (Pei et al., 2010).

The preparation of bacterial cellulose nanocrystals topochemically trimethylsilylated was also reported (Grunert and Winter, 2002a). Trimethylsilylation of the crystal surface was performed heterogeneously with hexamethyldisilazane in formamide. As determined by inductively coupled plasma spectrometry the average degree of substitution of these silylated nanocrystals was 0.49 , resulting in a molecular weight increase of $22 \%$ with respect to unmodified cellulose (Grunert and Winter, $2002 b)$. In other words, $18 \%$ of the silylated crystals weight was due to silyl groups. Resulting nanoparticles were dispersed in acetone to process nanocomposites with a cellulose acetate butyrate matrix.

Suspensions of MFC resulting from the homogenization of sugar beet pulp were surface silylated with isopropyl dimethylchlorosilane (Goussé et al., 2004). When mild silylation conditions were applied, the microfibrils retained their morphology, but could be dispersed in a non-flocculating manner into organic solvents. Permanent antimicrobial MFC films were also prepared by grafting quaternary ammonium compound octadecyldimethyl(3-trimethoxysilylpropyl) ammonium chloride (ODDMAC) by a simple adsorption-curing process (Andresen et al., 2007). MFC and ODDMAC were mixed in a mixture of methanol and water $(90: 10 \mathrm{w} / \mathrm{w})$. The mixture was cast, drained, dried and finally cured for $2 \mathrm{~h}$ at $100^{\circ} \mathrm{C}$. Hydrophobization of MFC was also obtained by grafting 3-aminopropyltriethoxysilane (APS) and 3-glycidoxypropyltrimethoxysilane (GPS) (Lu et al., 2008). MFC and coupling agents were mixed in acetone, and the mixture was filtered and dried. The reaction was carried out for $2 \mathrm{~h}$ at $120^{\circ} \mathrm{C}$. Better and stronger adhesion between MFC and the epoxy polymer used as matrix was observed for the treated fibers, which resulted in better mechanical properties of the composite materials.

\subsection{Carbamination}

Cellulose nanoparticles (both cellulose nanocrystals and MFC) extracted from sisal fibers were chemically modified with n-octadecyl isocyanate $\left(\mathrm{C}_{18} \mathrm{H}_{37} \mathrm{NCO}\right)$ (Siqueira et al., 2009). The surface chemical modification was carried out in toluene. Never-dried nanoparticles were used and a solvent exchange procedure from water to toluene was performed. The aqueous suspensions of cellulose nanoparticles were solvent exchanged to acetone and then to dry toluene by several successive centrifugation and redispersion operations. Contrarily to nanocrystals, it was found that MFC did not disperse homogeneously in toluene, probably because of the possibility of entanglements between the microfibrils and differences in surface charge. To overcome this problem, a process consisting in an in-situ solvent exchange procedure during the reaction was proposed. Compared to cellulose nanocrystals, a higher grafting density was necessary to achieve dispersion of MFC in an apolar and aprotic liquid medium. 
Hexamethylene diisocyanate was also used to modify the surface characteristics of MFC (Stenstad et al., 2008). Water from the MFC suspension was replaced by acetone and then by THF. The reaction was performed for $2 \mathrm{~h}$ at $50^{\circ} \mathrm{C}$. The results indicated that the treatments can be designed so that the strength properties or solubility of the MFC are not significantly changed.

\subsection{TEMPO-mediated oxidation}

Transformation of hydroxyl groups from the surface of cellulose nanoparticles into carboxylic groups can be conducted using 2,2,6,6-tetramethylpiperidine-1-oxyl (TEMPO) reagent (Isogai et al., 2011). TEMPO-mediated oxidation of cellulosic fibers is the most commonly used pretreatment to prepare MFC (see Chapter 2, Section 2.2.3). This type of nanocellulose is sometimes referred to as TEMPO-oxidized cellulose nanofibers (TOCN). Catalytic oxidation using TEMPO consists in a selective conversion of hydroxyl groups to aldehyde and carboxylate functional groups under aqueous and mild conditions.

Oxidation is broadly defined as the interaction between oxygen molecules and all the different substances they may contact. Technically, it is more precisely defined as the loss of at least one electron when two or more substances interact. These substances may or may not include oxygen. (2,2,6,6-tetramethylpiperidin-1-oxyl), or (2,2,6,6-tetramethylpiperidin-1-oxidany) or TEMPO is a stable nitroxyl radical (Figure 5.7) that was found to catalyze the oxidation of primary alcohol groups to aldehydes in aqueous media (De Nooy et al., 1995). This heterocycle is a red-orange, sublimable solid with a melting point around $36-38^{\circ} \mathrm{C}$, and it is widely used as a radical trap, structural probe for biological systems, reagent in organic synthesis, or mediator in controlled free radical polymerization. The actual oxidant is the $\mathrm{N}$-oxoammonium salt. In a catalytic cycle with sodium hypochlorite and sodium bromide as the stoichiometric oxidant, hypochlorous acid generates the N-oxoammonium salt from TEMPO.

The TEMPO-mediated oxidation reaction of cellulose is schematized in Figure 5.8. The TEMPO/ $\mathrm{NaBr} / \mathrm{NaClO}$ system in water at $\mathrm{pH} 10-11$ is expected to oxidize the $\mathrm{C} 6$ primary hydroxyls of cellulose to $\mathrm{C} 6$ carboxylate groups. $\mathrm{NaClO}$ is added to the aqueous suspension of cellulose in the presence of catalytic amounts of TEMPO and $\mathrm{NaBr}$ at room temperature. The C6 primary hydroxyl groups of cellulose are thus entirely and selectively converted to carboxylate groups via C6 aldehyde groups and only $\mathrm{NaClO}$ and $\mathrm{NaOH}$ are consumed (Saito and Isogai, 2006). TEMPO-mediated oxidation of cellulose nanocrystals involves a topologically confined reaction sequence, and as a consequence of the 2-fold screw axis of the cellulose chain, only half of the accessible hydroxymethyl groups are available to react, whereas the other half are buried within the crystalline particle (Habibi et al., 2006). 
<smiles>CC1(C)CCCC(C)(C)N1[O]</smiles>

Fig. 5.7: (2,2,6,6-tetramethylpiperidin-1-oxyl), or (2,2,6,6-tetramethylpiperidin-1-oxidany) or TEMPO radical.

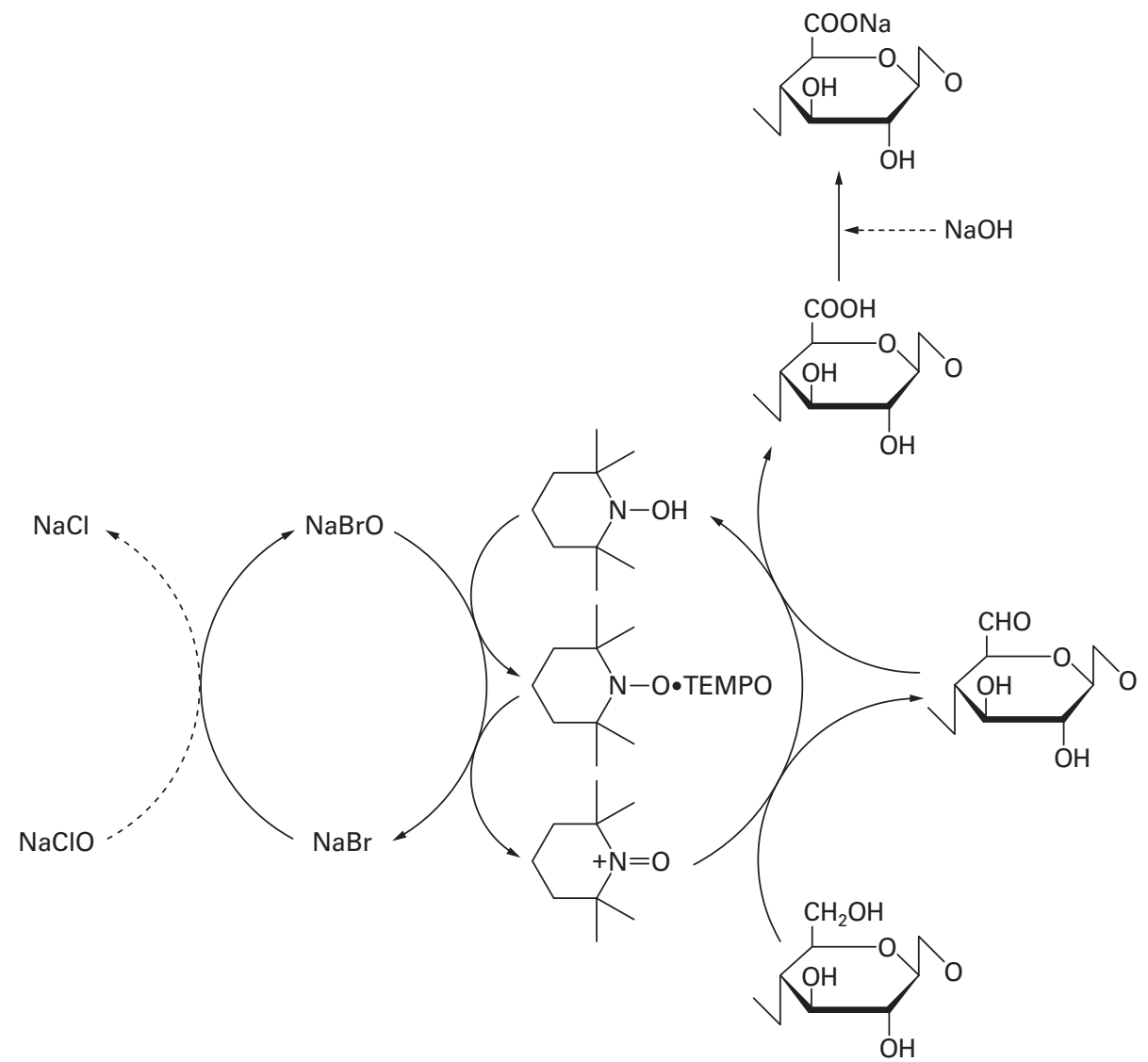

Fig. 5.8: Scheme of TEMPO-mediated oxidation of cellulose (Saito and Isogai, 2006).

However, undesirable side reactions under such alkaline conditions, like significant depolymerization of discoloration or the oxidized cellulose resulting from the presence of residual aldehyde groups, are unavoidable (Shibata and Isogai, 2003; Saito and Isogai, 2004). Indeed, these aldehyde groups are thermally unstable and cause discoloration of the oxidized cellulose when heated or dried over $80^{\circ} \mathrm{C}$ in the presence of residual acid. Moreover, they disturb the individualization of cellulose microfibrils 
in water due to the partial formation of hemiacetal linkages between fibrils (Saito and Isogai, 2006). To avoid these side reactions, a TEMPO/ $\mathrm{NaClO} / \mathrm{NaClO}_{2}$ system under neural or slightly acidic conditions was proposed as an alternative and applied (Saito et al., 2009). Catalytic amounts of TEMPO and $\mathrm{NaClO}$ are combined with $\mathrm{NaClO}_{2}$ as the primary oxidant.

Carboxylation of cellulose nanocrystals with the TEMPO/NaBr/NaClO at $\mathrm{pH}$ 10-11 and room temperature was used as an intermediate step to promote grafting of poly(ethylene glycol) chains (Araki et al., 2001). The carboxyl content of the carboxylated sample was $915 \mathrm{mmol} \cdot \mathrm{kg}^{-1}$. A homogeneous dispersion in water was obtained. TEMPO-mediated oxidation was also conducted on cotton linters cellulose nanocrystals and sugar beet MFC (Montanari et al., 2005). Most oxidized specimens tended to limit their aggregation and promote their individualization. Moreover, TEMPOmediated oxidation was found to induce cleavage in the amorphous zones of MFC and a decrease of the crystal size was observed. By applying various oxidation conditions to HCl-prepared tunicin nanocrystals, it was found that the degree of oxidation can be tuned (Habibi et al., 2006). With a degree of oxidation up to 0.1, the morphological integrity of the nanocrystals was kept and the surface hydroxymethyl groups were selectively converted to carboxylic groups, thus imparting a negative surface charge to the nanoparticles. Carboxyl content around $300 \mu \mathrm{mol} \cdot \mathrm{g}^{-1}$ was found to be necessary to significantly reduce the number of passes to obtain MFC gels (Besbes et al., 2011a; Besbes et al., 2011b).

TEMPO oxidation is often used to selectively activate the primary hydroxyl groups of cellulose nanoparticles by their conversion to carboxylic acids. Further reactions can be carried out using the activated TEMPO-oxidized nanoparticles. For instance, two separate populations of complementary single stranded DNAs were grafted to carboxylated cellulose nanocrystals and the populations were then combined to hybridize the DNA and bond the cellulosic nanoparticles (Mangalam et al., 2009). Grafting was performed using carbodiimide chemistry.

\subsection{Polymer grafting}

Surface chemical modification of cellulose nanoparticles can be achieved by covalently attaching small molecules as seen previously, but also polymers. Long chain surface chemical modification of cellulose nanoparticles consist in grafting agents bearing a reactive end group and a long "compatibilizing” tail. The general objective of this chemical modification is of course to increase the apolar character of the nanoparticle. In addition, it can yield some extraordinary possibilities. The surface grafted chains can act as binding sites for active agents in drug delivery systems or for toxins in purifying and treatment systems. These grafted chains may also be able to interdiffuse, upon heating, to form the polymer matrix phase. The covalent linkage between reinforcement and matrix will result in near-perfect stress transfer 
at the interface with exceptional mechanical properties of the composite as a result. Moreover, if the grafted chains and the matrix are the same, better compatibilization can be obtained thanks to the formation of a continuous interphase between the cellulose phase and the polymeric matrix. The possibility to obtain chain entanglements as well as for co-crystallization between covalently linked chains at the surface of

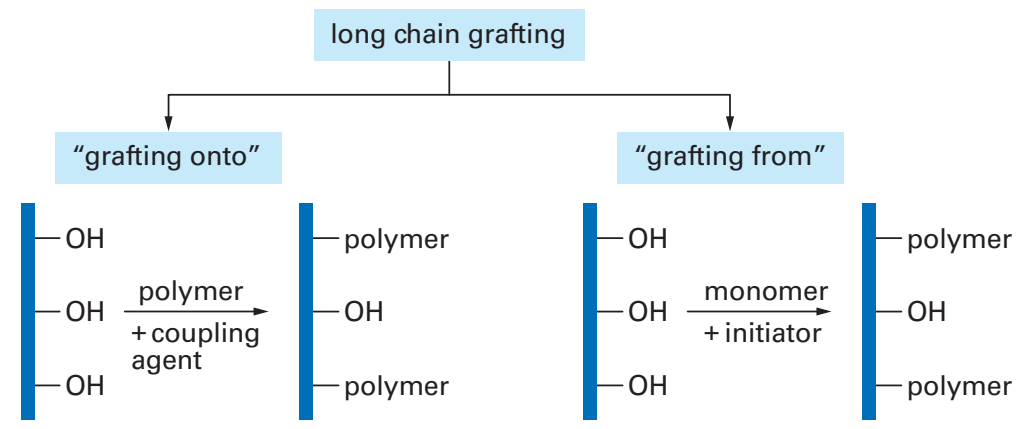

\footnotetext{
++ the polymers can be fully characterized before grafting (control the properties of the resulting material)

-- steric hindrance (\& high viscosity)

++ reaction fast + easy (no steric hindrance \& low viscosity)

- - grafted polymer not fully characterized
}

Fig. 5.9: Schematic representation of the "grafting onto" and "grafting from" approaches (Dufresne, 2010).

\begin{tabular}{|c|c|c|c|c|c|c|}
\hline & $\begin{array}{l}\text { Source of } \\
\text { Cellulose }\end{array}$ & $\begin{array}{l}\text { Nano- } \\
\text { particle }\end{array}$ & Polymer & Method & $\begin{array}{l}\text { Objective of the } \\
\text { Modification }\end{array}$ & Reference \\
\hline \multirow{6}{*}{ 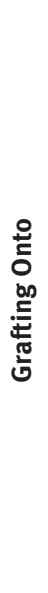 } & \multirow[t]{3}{*}{ Cotton } & \multirow[t]{3}{*}{$\mathrm{CNC}$} & PEG & $\begin{array}{l}\text { Carboxylation- } \\
\text { amidation }\end{array}$ & $\begin{array}{l}\text { Dispersion in water and } \\
\text { non-aqueous solvents }\end{array}$ & $\begin{array}{l}\text { (Araki et al., } \\
\text { 2001) }\end{array}$ \\
\hline & & & PEO & $\begin{array}{l}\text { Alkaline } \\
\text { epoxyde ROP }\end{array}$ & $\begin{array}{l}\text { Steric stabilization in } \\
\text { water }\end{array}$ & $\begin{array}{l}\text { (Kloser and } \\
\text { Gray, 2010) }\end{array}$ \\
\hline & & & PS, PtBuA & SI-ATRP & $\begin{array}{l}\text { Dispersion in organic } \\
\text { solvents }\end{array}$ & $\begin{array}{l}\text { (Harrisson et } \\
\text { al., 2011) }\end{array}$ \\
\hline & $\begin{array}{l}\text { Cotton } \\
\text { Linters }\end{array}$ & $\mathrm{CNC}$ & PEO-co-PPO & $\begin{array}{l}\text { Peptidic coup- } \\
\text { ling reaction }\end{array}$ & $\begin{array}{l}\text { Providing thermosensitive } \\
\text { properties }\end{array}$ & $\begin{array}{l}\text { (Azzam et al., } \\
\text { 2010) }\end{array}$ \\
\hline & \multirow[t]{2}{*}{ Ramie } & \multirow[t]{2}{*}{ CNC } & \multirow[t]{2}{*}{ PCL } & \multirow[t]{2}{*}{$\begin{array}{l}\text { Isocyanate- } \\
\text { mediated } \\
\text { reaction }\end{array}$} & $\begin{array}{l}\text { Dispersion in dichloro- } \\
\text { methane and compatibili- } \\
\text { zation with PCL }\end{array}$ & $\begin{array}{l}\text { (Habibi and } \\
\text { Dufresne, } \\
\text { 2008) }\end{array}$ \\
\hline & & & & & $\begin{array}{l}\text { Dispersion in DMF and } \\
\text { compatibilization with } \mathrm{PCL}\end{array}$ & $\begin{array}{l}\text { (Zoppe et al., } \\
\text { 2009) }\end{array}$ \\
\hline
\end{tabular}




\begin{tabular}{|c|c|c|c|c|c|c|}
\hline & $\begin{array}{l}\text { Source of } \\
\text { Cellulose }\end{array}$ & $\begin{array}{l}\text { Nano- } \\
\text { particle }\end{array}$ & Polymer & Method & $\begin{array}{l}\text { Objective of the } \\
\text { Modification }\end{array}$ & Reference \\
\hline \multirow{14}{*}{ 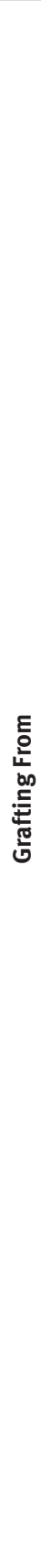 } & $\begin{array}{l}\text { Bleached } \\
\text { Birch Pulp }\end{array}$ & MFC & $\begin{array}{l}\text { PGMA, } \\
\text { PMMA, } \\
\text { PHEMA, } \\
\text { PBUA, PEA, }\end{array}$ & $\begin{array}{l}\text { Cerium-induced } \\
\text { reaction }\end{array}$ & Functionalization & $\begin{array}{l}\text { (Littunen et } \\
\text { al., 2011) }\end{array}$ \\
\hline & $\begin{array}{l}\text { Bleached } \\
\text { Spruce Sulfite } \\
\text { Cellulose }\end{array}$ & MFC & PGMA & $\begin{array}{l}\text { Cerium-induced } \\
\text { reaction }\end{array}$ & Functionalization & $\begin{array}{l}\text { (Stenstad et } \\
\text { al., 2008) }\end{array}$ \\
\hline & $\begin{array}{l}\text { Bleached } \\
\text { Wood Sulfite } \\
\text { Pulp }\end{array}$ & MFC & $\mathrm{PCL}$ & $\begin{array}{l}\mathrm{Sn}(\mathrm{Oct})_{2} \text {-cataly- } \\
\text { zed ROP }\end{array}$ & $\begin{array}{l}\text { Control of the molecular } \\
\text { weight of the grafted } \\
\text { polymer }\end{array}$ & $\begin{array}{l}\text { (Lönnberg et } \\
\text { al., 2008) }\end{array}$ \\
\hline & \multirow[t]{5}{*}{ Cotton } & \multirow[t]{5}{*}{ CNC } & PS & SI-ATRP & \multicolumn{2}{|c|}{$\begin{array}{l}\text { Investigation of liquid crys-(Yi et al., } \\
\text { talline phases behavior 2008) } \\
\text { in DMF }\end{array}$} \\
\hline & & & PMMAZO & SI-ATRP & $\begin{array}{l}\text { Investigation of liquid } \\
\text { crystalline phases beha- } \\
\text { vior in chlorobenzene }\end{array}$ & $\begin{array}{l}\text { (Xu et al., } \\
2008)\end{array}$ \\
\hline & & & PDMAEMA & SI-ATRP & $\begin{array}{l}\text { Investigation of liquid } \\
\text { crystalline phases beha- } \\
\text { vior in water }\end{array}$ & $\begin{array}{l}\text { (Yi et al., } \\
\text { 2009) }\end{array}$ \\
\hline & & & PS & SI-ATRP & $\begin{array}{l}\text { Pollutant removal from } \\
\text { water }\end{array}$ & $\begin{array}{l}\text { (Morandi et } \\
\text { al., 2009) }\end{array}$ \\
\hline & & & PAA & SI-LRP & \multicolumn{2}{|c|}{$\begin{array}{l}\text { Preparation of well-defined(Majoinen et } \\
\text { polymer brush architec- al., 2011) } \\
\text { tures }\end{array}$} \\
\hline & Cotton Linters & $\mathrm{CNC}$ & $\mathrm{PCL}$ & $\begin{array}{l}\mathrm{Sn}(\mathrm{Oct})_{2-}^{-} \\
\text {catalyzed ROP }\end{array}$ & $\begin{array}{l}\text { Dispersion in dichloro- } \\
\text { methane and compatibili- } \\
\text { zation with PLA }\end{array}$ & $\begin{array}{l}\text { (Lin et al., } \\
\text { 2009) }\end{array}$ \\
\hline & $\begin{array}{l}\text { Cottonseed } \\
\text { Linter Pulp }\end{array}$ & CNC & WPU & $\begin{array}{l}\text { In situ polymeri- } \\
\text { zation }\end{array}$ & $\begin{array}{l}\text { Direct processing of WPU- } \\
\text { based nanocomposites }\end{array}$ & $\begin{array}{l}\text { (Cao et al., } \\
2009 \text { ) }\end{array}$ \\
\hline & \multirow[t]{4}{*}{ Ramie } & \multirow[t]{4}{*}{ CNC } & $\mathrm{PCL}$ & $\begin{array}{l}\mathrm{Sn}(\mathrm{Oct})_{2} \text {-cataly- } \\
\text { zed ROP }\end{array}$ & $\begin{array}{l}\text { Dispersion in dichloro- } \\
\text { methane and compatibili- } \\
\text { zation with PCL }\end{array}$ & $\begin{array}{l}\text { (Habibi et al., } \\
\text { 2008) }\end{array}$ \\
\hline & & & $\begin{array}{l}\text { Poly } \\
\text { (NiPAAm) }\end{array}$ & SI-SET-LRP & Functionalization & $\begin{array}{l}\text { (Zoppe et al., } \\
2010)\end{array}$ \\
\hline & & & $\mathrm{PCL}$ & $\begin{array}{l}\mathrm{Sn}(\mathrm{Oct})_{2^{-}} \\
\text {catalyzed ROP }\end{array}$ & $\begin{array}{l}\text { Compatibilization } \\
\text { with } \mathrm{PCL}\end{array}$ & $\begin{array}{l}\text { (Goffin et al., } \\
\text { 2011a) }\end{array}$ \\
\hline & & & PLA & $\begin{array}{l}\mathrm{Sn}(\mathrm{Oct})_{2^{-}} \\
\text {catalyzed ROP }\end{array}$ & $\begin{array}{l}\text { Compatibilization } \\
\text { with PLA }\end{array}$ & $\begin{array}{l}\text { (Goffin et al., } \\
\text { 2011b) }\end{array}$ \\
\hline
\end{tabular}

Table 5.3: Polymer grafting of cellulosic nanoparticles. 
the nanoparticle with those from the matrix should further improve the mechanical properties of the final composite.

Two main different approaches can be used to graft polymers on surfaces, viz. "grafting onto" or "grafting from". These two strategies are schematized in Figure 5.9. The "grafting onto" approach consists in mixing the cellulosic nanoparticles with an existing polymer and a coupling agent to attach the polymer to the nanoparticle surface. In this approach, one cannot expect high grafting densities because of steric hindrance and blocking of reactive sites by the already grafted polymer chains. Moreover, the viscosity of the reaction medium is high because of the presence of macromolecular chains. However, its main advantage is that the properties of the resulting material are perfectly controlled since the molecular weight of the attached polymer can be characterized before grafting. The "grafting from" approach consists in mixing the cellulosic nanoparticles with a monomer and an initiator agent to induce the polymerization of the monomer from the nanoparticle surface. Because of the lower viscosity of the medium and limitation of steric hindrance, this strategy has proven to be a very effective way to create high grafting densities on the surface. However, it is difficult to control and determine precisely the molecular weight of the grafted polymer. Some of these studies are collected in Table 5.3.

\subsubsection{Polymer grafting using the "grafting onto" approach}

Cellulose nanocrystals obtained by acid hydrolysis of ramie fibers were subjected to isocyanate-mediated reaction to graft polycaprolactone (PCL) chains with various molecular weights $\left(\mathrm{Mn}=10,000 \mathrm{~g} \cdot \mathrm{mol}^{-1}\right.$ and $\left.\mathrm{Mn}=42,500 \mathrm{~g} \cdot \mathrm{mol}^{-1}\right)$ on their surface (Habibi and Dufresne, 2008). Never-dried nanocrystals were used for the grating and a solvent exchange procedure from water to toluene was performed. For that, aqueous suspension with the desired amount of cellulose nanocrystals (1 wt $\%$ ) was solvent exchanged to acetone and then to dry toluene by several successive centrifugation and redispersion operations. Sonication was performed after each solvent exchange step to avoid aggregation. However, the suspension in toluene was not stable in time. PCL grafting onto cellulose nanocrystals involved a three-step process. The first step required the reaction of the polymer on isocyanate functionality of phenylisocyanate. The second step involved the reaction of the polymer, now protected, with one isocyanate functionality of toluene 2,4-diisocyanate (2,4-TDI). During the third step, the unreacted second isocyanate functionality of 2,4-TDI was then reacted with the surface hydroxyl groups of the cellulose nanocrystals to graft the polymer chain onto the nanoparticles. Each mixture was washed with toluene, with successive centrifugations and then washed with dichloromethane by successive centrifugations to remove ungrafted polymer chains. The washed modified nanocrystals were subsequently Soxhlet extracted with dichloromethane before drying in a convective oven. The reaction scheme is shown in Figure 5.10. 
(I)

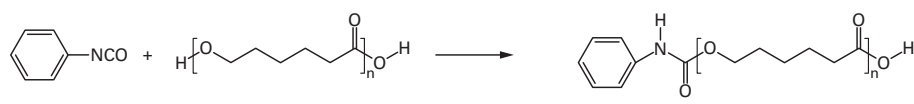

(II) $\mathrm{OCN}$
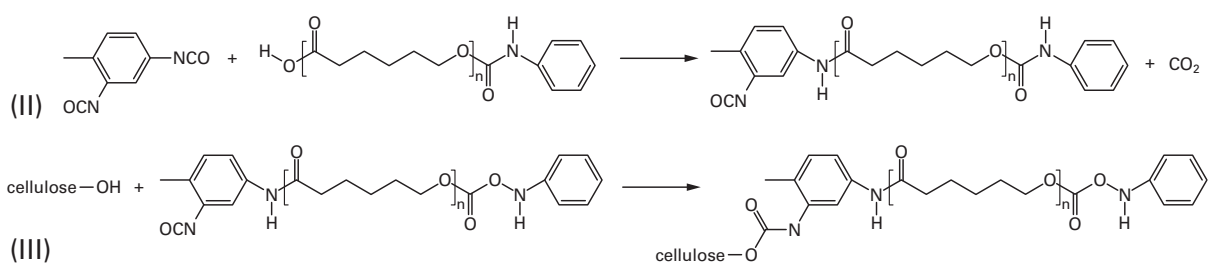

Fig. 5.10: Reaction scheme of the grafting of PCL onto the cellulose nanocrystals surface: (I) capping of the second hydroxyl group of PCL chain end, (II) reaction of the PCL chain with 2,4-TDI to give rise to the grafting agent, and (III) grafting onto the cellulose nanocrystal (adapted from Labet et al., 2007).

Grafted polymeric chains were found to form a crystalline structure at the surface of the nanoparticles as evidenced from X-ray diffraction and differential scanning calorimetry experiments. Nanocomposite films were processed from both unmodified and PCL-grafted nanoparticles, and PCL as matrix using a casting/evaporation technique. It was shown that mechanical properties of resulting films were notably different. Compared to unmodified nanoparticles, the grafting of PCL chains on the surface resulted in lower modulus values but significantly higher strain at break.

Poly(ethylene glycol) chains with a terminal amino group on one end (PEG- $\mathrm{NH}_{2}$, $\mathrm{Mw}=1,000$ ) have been grafted onto the surface of hydrochloric acid-prepared cellulose nanocrystals using a carboxylation-amidation procedure (Araki et al., 2001). Amidation was performed using a water-soluble carbodiimide, 1-ethyl-3-(3-dimethylaminopropyl) carbodiimide (EDC), and N-hydroxysuccinimide (NHS). The freezedried PEG-grafted nanocrystals could be redispersed in water or non-aqueous solvents and displayed drastically enhanced dispersion stability evidenced through resistance to addition of $2 \mathrm{M}$ sodium chloride. The amount of bound PEG was 0.2$0.3 \mathrm{~g} \cdot \mathrm{g}^{-1}$ of cellulose. In order to achieve higher steric instead of electrostatic stabilization, aqueous suspensions of poly(ethylene oxide) (PEO)-grafted cotton nanocrystals were prepared (Kloser and Gray, 2010). Desulfation of sulfuric acid-prepared nanocrystals was carried out with sodium hydroxide and the nanoparticles were functionalized with $\alpha$-epoxy, $\omega$-methoxy-terminated PEO $\left(\mathrm{Mw}=2,086 \mathrm{~g} \cdot \mathrm{mol}^{-1}\right)$ under alkaline conditions. Preformed amine-terminated polystyrene and poly(tert-butyl acrylate) $(\mathrm{PtBuA}$ ) were grafted onto oxidized cellulose nanocrystals (Harrisson et al., 2011). Thermogravimetric analysis (TGA) was used to estimate the grafting density at around $60-64 \%$.

Grafting of thermosensitive amine-terminated statistical Jeffamine copolymers (PEO-co-PPO) onto the surface of cellulose nanocrystals was achieved by a peptidic coupling reaction (Azzam et al., 2010). TEMPO-oxidized nanocrystals were used and 
the polymer grafting reaction was performed either in water or in DMF. The grafting density was sufficiently high to induce a steric stabilization of the nanocrystals that prevented flocculation at high ionic strength and made them surface-active. Amidation of TEMPO-oxidized nanocrystals was also performed with 4-amino TEMPO, a nitroxide radical containing a terminal amino group (Follain et al., 2010). The amine coupling brought a low polarity to the nanoparticles enabling the modification of cellulose suspensions into hydrophobic materials.

\subsubsection{Polymer grafting using the "grafting from" approach}

Several studies reported the preparation of PCL-grafted cellulose nanoparticles using the "grafting from" strategy. PCL is traditionally prepared by the ring-opening polymerization (ROP) of cyclic $\varepsilon$-caprolactone monomer. The catalytic ROP of lactones is the most common synthesis route today and can be carried out in solution by cationic, anionic or coordination-insertion mechanisms depending on the catalyst used. Stannous octoate $\left(\mathrm{Sn}(\mathrm{Oct})_{2}\right)$ is the most commonly used catalyst in ROP due to its high effectiveness and low toxicity (Storey and Sherman, 2002; Kowalski et al., 2005). In ROP, the hydroxyl groups on the cellulose nanoparticle surface act as initiator and the ratio of monomer to initiating groups determines the DP of the grafted polymer chains (Figure 5.11(a)).

(a)
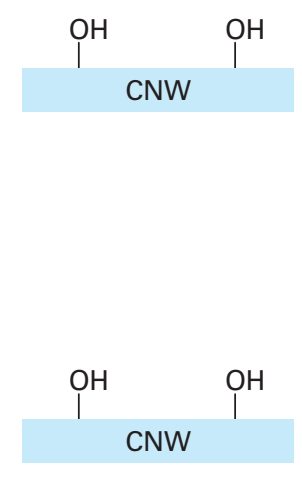

(b)

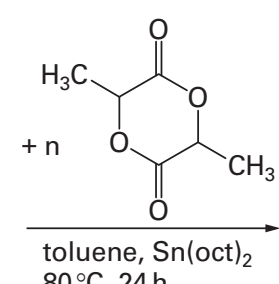

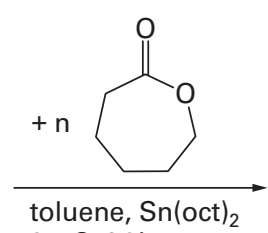

$95^{\circ} \mathrm{C}, 24 \mathrm{~h}$

$80^{\circ} \mathrm{C}, 24 \mathrm{~h}$
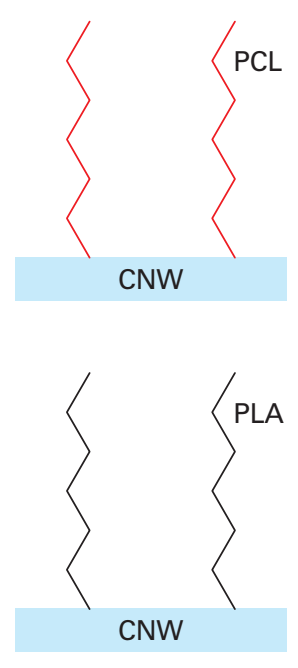

Fig. 5.11: Ring opening polymerization of (a) caprolactone (Goffin, 2010) and (b) L-lactide (Goffin et al., 2011b) as initiated from the surface of cellulose nanocrystals (CNW). 
This approach was used to prepare PCL-grafted ramie (Habibi et al., 2008) and native linter (Lin et al., 2009) cellulose nanocrystals. PCL was grafted by Sn(Oct) ${ }_{2}$-catalyzed ROP.

In the former study (Habibi et al., 2008), the $\mathrm{H}_{2} \mathrm{SO}_{4}$-hydrolyzed cellulose nanocrystals were neutralized using a $1 \mathrm{wt} \% \mathrm{NaOH}$ solution and never-dried nanoparticles were used by exchanging water to acetone and then to dry toluene by successive centrifugation and redispersion operations. The grafting reaction was performed at $95^{\circ} \mathrm{C}$ for $24 \mathrm{~h}$ and stopped by adding a few drops of dilute hydrochloric acid solution. The grafting efficiency was evidenced by the long-term stability of suspension of PCLgrafted cellulose nanocrystals in toluene. After PCL grafting, the structural and morphological integrity of the cellulose nanocrystals did not appear to have been affected by $\mathrm{Sn}(\mathrm{Oct})_{2}$-catalyzed polymerization and grafting as shown by comparing the TEM observation of ungrafted and grafted nanoparticles (Figure 5.12). The cellulose nanocrystal content in the recovered nanohybrid sample was determined by gravimetry and estimated to $15 \mathrm{wt} \%$. The nanocrystals were less individualized than native ones and were believed to aggregate as a result of sulfate groups being removed from their surface. Furthermore, the presence of hydrophobic PCL chains on the nanocrystals likely triggers the particle aggregation upon drying. Nanocomposites with high filler content were prepared from neat and PCL-grafted cellulose nanocrystals and high molecular weight PCL as matrix using a casting/evaporation technique from dichloromethane. These PCL-grafted cellulose nanocrystals were also used as "masterbatches” by melt blending with a PCL matrix (Goffin et al., 2011a).
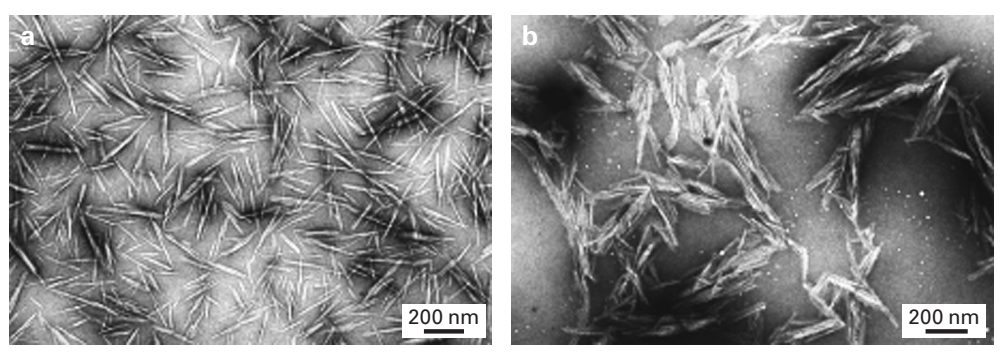

Fig. 5.12: Transmission electron micrograph of ramie cellulose nanocrystals: (a) ungrafted and (b) recovered after ROP/grafting reactions and Soxhlet extraction (Habibi et al., 2008).

In the second investigation (Lin et al., 2009), cellulose nanocrystals were freeze-dried and ROP was carried out using microwave irradiation. Purification and removal of residual monomer, catalyst and homopolymer were obtained by dispersion of the grafted nanocrystals in $\mathrm{CH}_{2} \mathrm{Cl}_{2}$ and precipitation by methanol. Processing of nanocomposites was performed in $\mathrm{CH}_{2} \mathrm{Cl}_{2}$ using poly(lactic acid) (PLA) as matrix and casting/evaporation. 
A similar approach was used to graft PCL on the surface of MFC. Freeze-dried MFC was mixed with $\varepsilon$-CL monomer and grafting reaction was conducted with a catalytic amount of $\operatorname{Sn}(\mathrm{Oct})_{2}$ at $95^{\circ} \mathrm{C}$ for $18-20 \mathrm{~h}$ (Lönnberg et al., 2008). Because the number of initiating hydroxyl groups on the surface of MFC was unknown, a co-initiator, benzyl alcohol, which is known to be an efficient initiator for ROP of lactones in the presence of $\mathrm{Sn}(\mathrm{Oct})_{2}$, was added to the polymerization system to control the polymerization. Therefore, both free PCL and PCL-grafted MFC were formed simultaneously in the reaction medium. The soluble PCL formed was isolated from the mixture via filtration after dispersion of the reaction product in THF. By changing the amount of added free initiator to monomer, the amount of PCL on the MFC surface was changed to optimize the graft length. Different theoretical lengths of the PCL chain, i.e. DP 300, 600 and 1200, were investigated. The experimental molecular weights of free PCL formed during the grafting reaction were estimated from NMR and size exclusion chromatography (SEC). As expected, the obtained values were significantly lower than the theoretical ones since the theoretical molecular weight was calculated from the ratio of added monomer to free initiator, whereas the experimental value depends on the added monomer to free initiator, as well as the number of initiating groups on the MFC surface. TGA was used to estimate the composition of PCL-grafted MFC and PCL contents of $16 \%, 19 \%$ and $21 \%$ were reported, depending on the amount of free initiator to the system. Crystallization of grafted PCL was observed, but because of lower mobility of these chains compared to free PCL, a lower melting point and degree of crystallinity, as well as longer crystallization time were reported.

Molecular dynamics simulation was used to estimate the work of adhesion based on surface energies with different amounts of grafted caprolactone (Bergenstråhle et al., 2008). The types of interactions were principally Coulomb interactions, although the importance of weak Lennard-Jones interactions was larger when the surrounding medium was caprolactone instead of water. Hydrogen bonds were formed extensively between the grafted caprolactone and the surrounding medium.

Another biodegradable polyester, viz. polylactic acid (PLA), was chemically grafted on the surface of cellulose nanocrystals using the "grafting from" approach. $\mathrm{Sn}(\mathrm{Oct})_{2}$-catalyzed ROP of L-lactide was initiated from the hydroxyl groups available at the nanoparticle surface as shown in Figure 5.11(b) to yield PLA-grafted cellulose nanocrystal nanohybrids. The cellulose nanocrystals were neutralized using a $1 \mathrm{wt} \%$ $\mathrm{NaOH}$ solution and never-dried nanoparticles were used by exchanging water to acetone and then to dry toluene by successive centrifugation and redispersion operations. The grafting reaction was performed at $80^{\circ} \mathrm{C}$ for $24 \mathrm{~h}$ and stopped by adding a few drops of dilute hydrochloric acid solution. The surface-modified cellulose nanocrystals were recovered by precipitation with cold methanol, filtered, and dried at $40^{\circ} \mathrm{C}$ under vacuum until constant weight. The cellulose nanocrystal content in the recovered nanohybrid sample was determined by gravimetry and estimated to 14 wt $\%$. They were subsequently extruded and injection-molded with PLA. 
The cerium (IV) ion is a powerful oxidation agent for alcohol containing 1,2-glycol groups. The mechanism of ceric ion reaction involves the formation of a chelate complex that decomposes to generate free radicals on the cellulose backbone. Epoxy functionality was introduced onto the surface of MFC by oxidation by cerium (IV) followed by graft polymerization of glycidyl methacrylate (GMA) (Stenstad et al., 2008). The cerium-induced grafting reaction was performed using ammonium cerium (IV) nitrate at $35^{\circ} \mathrm{C}$ in dilute $(0.1 \mathrm{wt} \%)$ aqueous MFC suspensions. The length of the grafted polymeric chain was varied by regulating the amount of glycidyl methacrylate between 2 and $40 \mu \mathrm{mol} \cdot \mathrm{mg}^{-1} \mathrm{MFC}$. Significant degradation of the cellulose chains could occur because of the formation of radicals in the reaction involving ammonium cerium nitrate. However, it was shown that the treatment resulted in only a slight reduction in the molecular weight of cellulose. In the same study (Stenstad et al., 2008), coupling of MFC with maleic anhydride was shown to introduce vinyl groups that could be used as a starting point for grafting reactions for monomers that are insoluble in water, as an alternative to the cerium-induced grafting method. MFC was also grafted in aqueous solution using a redox-initiated free radical polymerization with two acrylates and three methacrylates (Littunen et al., 2011). Cerium ammonium nitrate was used as initiator. The graft copolymerization was dominant over homopolymerization for all monomers. The highest graft yield was obtained with butyl acrylate (BuA) and glycidyl methacrylate (GMA) with $80 \mathrm{wt} \%$. However, it was shown that $\mathrm{BuA}$ formed very long chains while for GMA relatively short chains were obtained forming a dense coating.

Cellulose nanocrystal reinforced waterborne polyurethane (WPU) nanocomposites have been prepared via one-pot polymerization, surface grafting, and processing (Cao et al., 2009). Polycaprolactone diol and isophorone diisocyanate (IPDI) were reacted to prepare a WPU prepolymer. During the reaction, cellulose nanocrystals dispersed in DMF were added to promote the reaction between hydroxyl groups from the nanoparticle surface and isocyanate on the end of the WPU prepolymer. Nanocomposites were processed by casting and evaporation. The grafted chains were able to form a crystalline structure on the surface of the nanoparticles and induced the crystallization of the matrix.

Grafting of polymer chains on cellulose nanoparticles can also be performed via living (or controlled) radical polymerization (LRP). Two steps are involved in LRP. The first one is the initial formation of initiating sites for LRP, in which an initiator is immobilized on the nanoparticle. The second step involves the reaction of the initiator-modified nanoparticles with a monomer to induce the polymerization. Coppermediated LRP is generally chosen for its versatility with respect to monomer choice and ease of synthesis. Depending on the reaction conditions, two mechanisms, atom transfer radical polymerization (ATRP) and single electron transfer-living radical polymerization (SET-LRP), are distinguished.

Cellulose nanocrystals were grafted with styrene by ATRP (Yi et al., 2008). The surface hydroxyl groups were esterified with 2-bromoisobutyrylbromide to yield 
2-bromoisobutyryloxy groups, which were used to initiate the polymerization of polystyrene (PS). The immobilization of ATRP initiator was conducted using freeze-dried nanocrystals redispersed in THF at room temperature for $24 \mathrm{~h}$ and the polymerization was performed at $110^{\circ} \mathrm{C}$ for $12 \mathrm{~h}$. The grafted PS chains were cleaved from the nanoparticles under acidic conditions and found to represent $68 \mathrm{wt} \%$ of the nanohybrid. They had a number-average molecular weight of $74,700 \mathrm{~g} \cdot \mathrm{mol}^{-1}$. The chiral-nematic selfordering of the grafted nanocrystals was investigated. A similar method was used to graft poly[6-(4-(4-methoxyphenylazo)phenoxyl)hexyl methacrylate] (PMMAZO) (Xu et al., 2008) and poly(N,N-dimethylaminoethyl methacrylate) (PDMAEMA) (Yi et al., 2009). For PMMAZO, the grafting percentage was determined from DSC measurements and found to be $74.6 \%$ (Xu et al., 2008). The number-average molecular weight of grafted PDMAEMA was estimated at around $10,200 \mathrm{~g} \cdot \mathrm{mol}^{-1}$ by cleaving from the cellulose backbone under acidic conditions (Yi et al., 2009). Surface-initiated ATRP was also used to prepare a range of PS-grafted nanocrystals with different graft lengths (theoretical DP = 27-171) and tailor grafting density by controlling the final content of initiating sites (Morandi et al., 2009). The grafted nanoparticles exhibited the capacity to absorb the equivalent of $50 \%$ of their weight of 1,2,4-trichlorobenzene from water proving their potential for pollutant removal applications.

Cellulose nanocrystals were grafted with thermoresponsive poly(N-isopropylacrylamide) (poly(NiPAAm) brushes via surface-initiated SET-LRP under various conditions at room temperature (Zoppe et al., 2010). Cu(I) was rapidly disproportionated to $\mathrm{Cu}(0)$ and $\mathrm{Cu}(\mathrm{II})$ yielding simple catalyst removal. It was shown that by increasing the initiator and monomer contents, increased amounts of poly(NiPAAm) were grafted from the surface of cellulose nanocrystals. Saponification of ester linkages was performed to cleave the polymer brushes from the cellulose nanoparticles. Increased molecular weights of polymer brushes were obtained when increasing the initiator and monomer contents. The observed effect of the initiator content was explained by local heterogeneities shifting the SET-LRP equilibrium to the active state. However, a broad molecular weight distribution was observed. Well-defined polymer brush architectures were prepared from cellulose nanocrystal surfaces to yield high grafting density polyelectrolyte brushes of poly(acrylic acid) (PAA) of different lengths by applying the Cu-mediated surface-initiated LRP (Majoinen et al., 2011). Chemical vapor deposition (CVD) was used as a pretreatment method before performing esterification in solution and obtaining full functionalization of the cellulose nanocrystal surface hydroxyl groups keeping the integrity of the cellulose crystal. Well-defined poly(tert-butyl acrylate) (PtBA) brushes with high grafting density were first synthesized from the nanocrystal surfaces, followed by the acid hydrolysis of their tertiary alkyl functionalities to provide PAA brushes. 


\subsection{Click chemistry}

Click chemistry is tailored to generate substances quickly and reliably by joining small units together. One of the most popular reactions within the click chemistry concept is the azide alkyne Huisgen cycloaddition using a copper catalyst at room temperature.

A method for the grafting of amine-terminated monomers onto surface-modified cellulose nanocrystals followed by click chemistry was reported (Filpponen and Argyropoulos, 2010). Initially, the primary hydroxyl groups on the surface of the nanoparticles were selectively activated to carboxylic acids using TEMPO-mediated hypohalite oxidation. Next, compounds carrying terminal amine functionality were grafted onto the surface of the nanocrystals using these reactive sites for the amidation reaction. The grafted amine compounds contained terminal alkyne or azide functionalities providing the essential precursors to click chemistry. Unique nanoplatelet gels were obtained from this method. Production of a heterogeneous system with facile anion exchange capability was also reported (Eyley and Thielemans, 2011). Imidazoliumbromide salt was grafted onto cellulose nanocrystals using click chemistry. The first step consisted in a chlorination to activate the nanocrystals. The chlorinated nanocrystals were subsequently azidated using sodium azide in DMF. The ionic liquid 1-methyl-3-propargylimidazolium bromide ([MPIM][Br]) was synthesized and grafted onto the azidated nanocrystals in an aqueous solution using $\mathrm{Cu}$ (II) sulfate as a pre-catalyst and sodium ascorbate as the reductant. The crystallinity index of the nanoparticle was found to decrease slightly from 0.89 to 0.80 during the chlorination step but remained constant through the other modification reactions.

\subsection{Fluorescently labeled nanocellulose}

Fluorescent labeling corresponds to the process of covalently attaching a fluorophore to another molecule, such as a protein or nucleic acid. This is generally accomplished using a reactive derivative of the fluorophore that selectively binds to a functional group contained in the target molecule. Fluorescence techniques have been extensively used to study the cellular uptake and biodistribution of nanoparticulate delivery systems, by tracking the localization of the fluorophores. The fluorophore absorbs light energy of a specific wavelength and re-emits energy at a longer wavelength. The most commonly labeled molecules are antibodies, proteins, amino acids and peptides which are then used as specific probes for detection of a particular target.

It is believed that cellulose nanocrystals are promising candidates for applications in nanomedicine (Dong and Roman, 2007). To enable the use of fluorescence techniques in in vitro and in vivo studies, cellulose nanocrystals can be labeled with fluorophores. Fluorescein-5'-isothiocyanate (FTIC) was used to label cellulose nanocrystals prepared from softwood sulfite pulp via a three-step reaction involving epoxy activation on the nanoparticle surface, opening of the epoxy rings with ammonium 
hydroxide, and coupling of FITC molecules to the primary amino groups (Dong and Roman, 2007). The reaction route is shown in Figure 5.13(a). The FITC content grafted to cellulose nanocrystals was determined by UV/Vis spectroscopy and was estimated to be $0.03 \mathrm{mmol} \cdot \mathrm{g}^{-1}$ of cellulose, equivalent to 5 FITC moieties per 1,000 anhydroglucose units. Figures 5.13(b) and 5.13(c) show aqueous suspensions of unlabeled and FITC-labeled cellulose nanocrystals, respectively. The unlabeled suspension was colorless and slightly opaque, whereas the FITC-labeled suspension appeared clear and yellow.

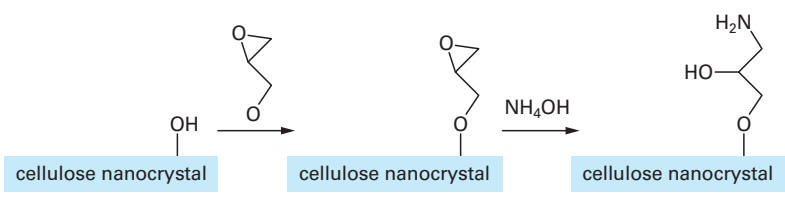

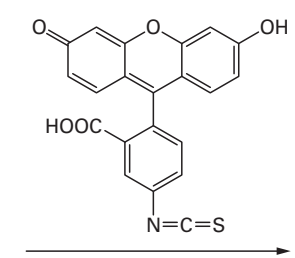

(a)

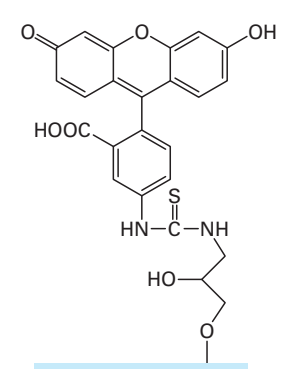

cellulose nanocrystal

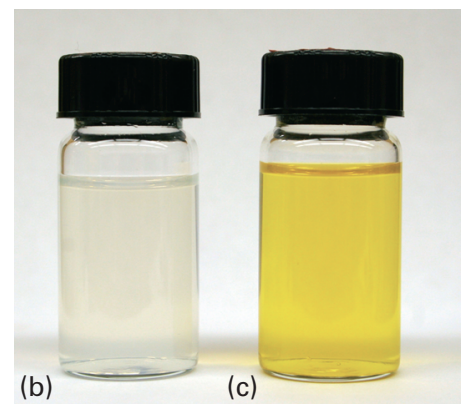

(b)

(c)

Fig. 5.13: (a) Reaction route for surface fluorescently labeled cellulose nanocrystals with FITC, and aqueous suspensions of (b) unlabeled cellulose nanocrystals (0.8 wt\%) and (c) FITC-labeled cellulose nanocrystals (0.5 wt\%) (Dong and Roman, 2007).

Cellulose nanocrystals prepared from cotton were converted into ratiometric $\mathrm{pH}$-sensing nanoparticles by dual fluorescent labeling using a one-pot procedure (Nielsen et al., 2010). FTIC and rhodamine B isothiocyanate (RBITC) were reacted with the free hydroxyl groups of cellulose nanocrystals in a basic solution forming a thiocarbamate bond. The average amount of FITC and RBITC attached to the cellulose nanocrystals was estimated by UV/Vis and fluorescence spectroscopy, respectively. Values of $2.8 \mu \mathrm{mol} \cdot \mathrm{g}^{-1}$ and $2.1 \mu \mathrm{mol} \cdot \mathrm{g}^{-1}$ of cellulose were reported for FITC and RBITC, respectively. In the same study, a versatile three-step procedure schematized in Figure 5.14 was reported, extending the number of fluorophores available for grafting. An amine group was introduced via esterification followed by a thiol-ene click reaction. The esterification was carried out by reacting the nanocrystals with methacrylic acid using N,N'-diisopropylcarbodiimide/4-dimethylaminopyridine as catalyst to introduce a double bond. The ensuing nanoparticles were reacted with cysteamine in 
methanol to introduce the primary amine. Two different $\mathrm{pH}$ sensitive fluorophores 5-(and-6)-carboxyfluorescein succinimidyl ester (FAM-SE) and Oregon Green 488 carboxylic acid, succinimidyl ester (OG-SE) were conjugated to two separate batches of cellulose nanocrystals along with the reference fluorophore 5-(and-6)-carboxytetramethylrhodramine succinimidyl ester (TAMRA-SE). The average amount of dye grafted to the nanoparticles was $10.4 \mu \mathrm{mol} \cdot \mathrm{g}^{-1} \mathrm{FAM}-\mathrm{SE}, 4.7 \mu \mathrm{mol} \cdot \mathrm{g}^{-1} \mathrm{TAMRA}-\mathrm{SE}$, and $7.3 \mu \mathrm{mol} \cdot \mathrm{g}^{-1} \mathrm{OG}-\mathrm{SE}, 4.2 \mu \mathrm{mol} \cdot \mathrm{g}^{-1} \mathrm{TAMRA}-\mathrm{SE}$, respectively.
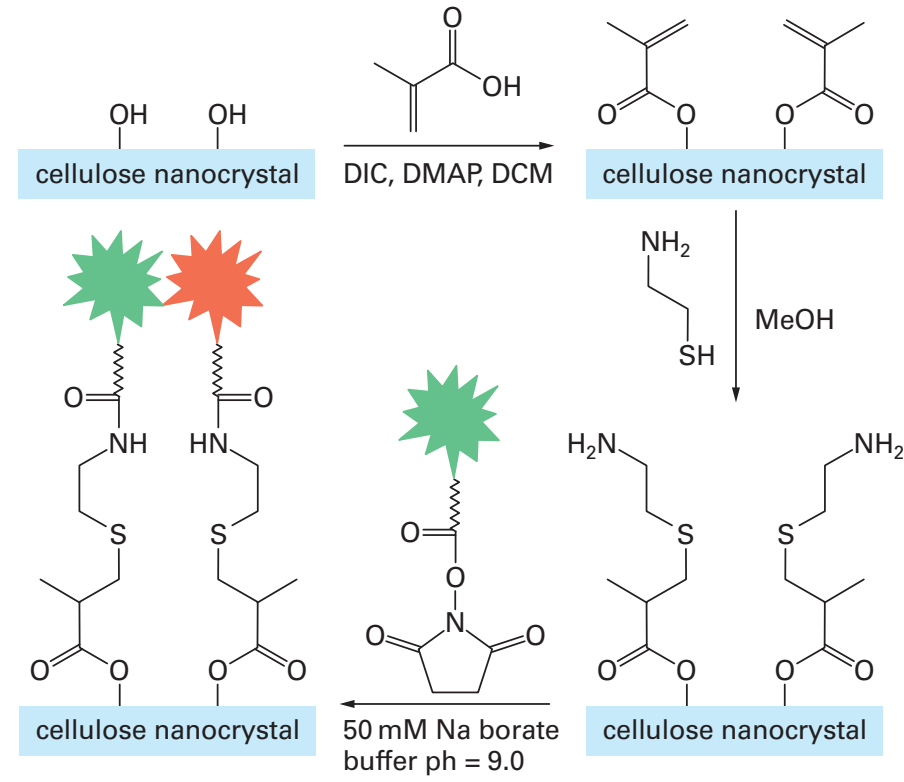

Fig. 5.14: Fluorescent labeling of cellulose nanocrystals with succinimidyl ester dyes (Nielsen et al., 2010).

Probing of cellular uptake and cytotoxicity was conducted for FITC and RBITC labeled cellulose nanocrystals (Mahmoud et al., 2010). No noticeably cytotoxic effect was observed, rendering modified cellulose nanocrystals as promising candidates for bioimaging and drug delivery systems.

Amino acids are the building blocks of proteins and peptides and are involved in the development of a wide range of biocompatible applications and architecture. TEMPO-oxidized MFC was coupled with fluorescent amino acids using a two-step procedure (Barazzouk and Daneault, 2011). First, MFC was activated by N-ethyl-N'(3-dimethylaminopropyl) carboiimide hydrochloride, forming a stable active ester in the presence of N-hydroxysuccinimide. Then, the active ester was reacted with the amino groups on the amino acids, forming an amide bond between MFC and amino acids. After coupling with amino, MFC clearly showed the characteristic absorption 
and fluorescence features of the grafted amino acid. Anchoring of L-leucine moieties to cellulose nanocrystals allowing the creation of a binding site to which drugs or targeting molecules can be attached was also reported (Cateto and Ragauskas, 2011). The chemical modification of cellulose nanocrystals with L-leucine amino acid by esterification reaction was conducted through a two-step process involving the reaction between Fmoc-L-leucine and cellulose and removal of Fmoc-protecting group.

\subsection{Evidence of surface chemical modification}

Regardless of the grafting strategy adopted, extensive washing, Soxhlet extraction or solubilization-centrifugation should be performed before characterization to remove ungrafted species. Several techniques are generally simultaneously used to evidence the surface chemical grafting of the nanoparticles.

\subsubsection{X-ray diffraction analysis}

It is important to verify that the X-ray diffraction pattern remains unchanged after chemical modification compared to the pristine sample and still displays the characteristics of cellulose I. The X-ray diffraction pattern of cellulose I is characterized by the main diffraction signals at $2 \theta$ values of $15^{\circ}, 16^{\circ}, 22.5^{\circ}$ and $34^{\circ}$ attributed to the diffraction planes 101, 101, 002 and 040, respectively. If only the surface of the nanoparticle is chemically modified, the initial crystallinity should be retained. If the grafted chains are able to crystallize at the surface of the nanoparticle, extra diffraction peaks could be observed, corresponding to the crystalline brush surrounding the nanoparticle (Habibi and Dufresne, 2008; de Menezes et al., 2009).

\subsubsection{Dispersion in organic solvent}

A simple and valuable experiment to evidence the surface chemical modification efficiency consists in trying to suspend the modified nanoparticles in an organic solvent and comparing the stability of the suspension to neat nanoparticles. The unmodified nanoparticle suspension should settle more rapidly than modified nanoparticles. However, in some cases and particularly for polymer-grafted nanoparticles, one cannot exclude that free (ungrafted) species can interact with cellulose and behave as a surface-compatibilizer. A simple physical mixture of pristine cellulose nanoparticles and the surface chemical modifier can be prepared in the same proportion and observed under the same conditions. Examples are provided in Figure 5.15. After stopping the stirring agitation, all suspensions are turbid. However, differences appear in the long-term dispersion stability. Only the polymer-grafted suspensions remain 
turbid and homogeneous while the supernatant of other suspensions becomes clear and colorless. Polymer chains grafted on cellulose nanocrystal surface are highly solvated maintaining the nanoparticles in stable suspension in the organic solvent. However, this method also depends on many parameters such as DS.
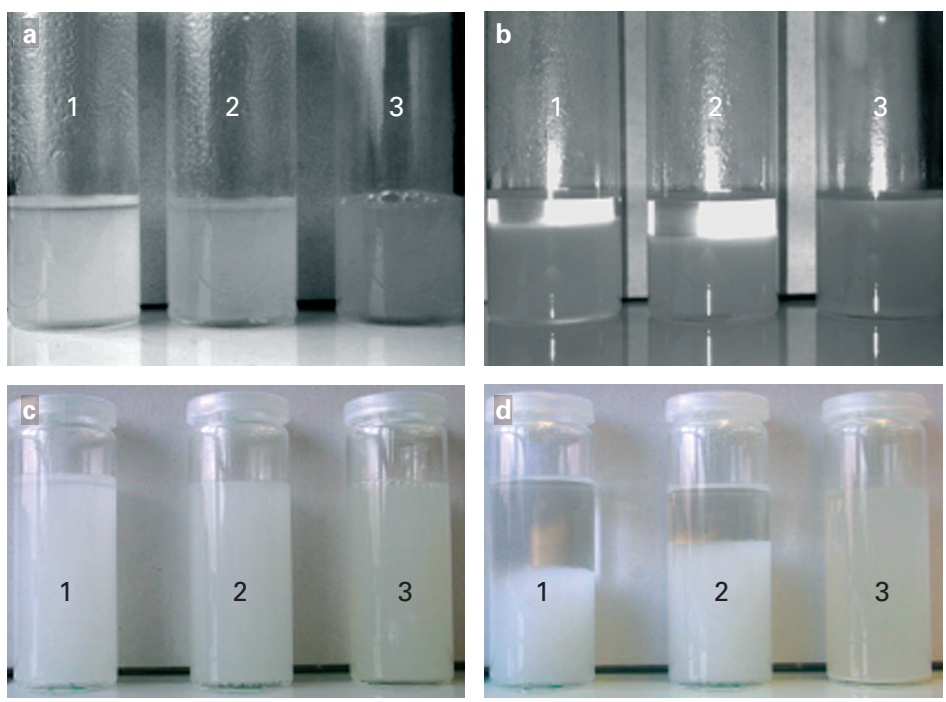

Fig. 5.15: (a), (b) Suspensions in toluene of (1) neat cellulose nanocrystal, (2) PCL and cellulose nanocrystals physical mixture, and (3) PCL-grafted cellulose nanocrystals (Habibi et al., 2008). Pictures recorded (a) immediately after stopping the stirring agitation and (b) 15 min later. (c), (d) Suspensions in chloroform of (1) neat cellulose nanocrystal, (2) PLA and cellulose nanocrystals physical mixture, and (3) PLA-grafted cellulose nanocrystals (Goffin et al., 2011b). Pictures recorded (c) immediately after stopping the stirring agitation and (d) $72 \mathrm{~h}$ later.

Another similar method consists in mixing the pristine or modified materials with two immiscible solvents, both with different polarities and densities and to observe with which solvent they are the best wetted. This gives a qualitative indication about the affinity between these two substances (Angellier et al., 2005).

\subsubsection{Contact angle measurements}

The contact angle is the angle at which a liquid/vapor interface meets a solid surface. If the liquid molecules are strongly attracted by the molecules of the solid surface (for example, water on hydrophilic cellulose) then a drop of the liquid tends to spread out on the solid surface, leading to a low contact angle value. Typically, the contact angle of water on a cellulose nanocrystal film surface ranges between $13^{\circ}$ and $29^{\circ}$ (Anglès 
and Dufresne, 2000; Eriksson et al., 2007; Aulin et al., 2009; Dankovich and Gray, 2011). Roughness of the cellulosic substrate can explain the dispersion in values. Upon hydrophobization of the nanoparticles, weaker attractions between water and solid molecules result in higher contact angles.

The dispersive and polar components of the surface energy of cellulose nanoparticles before and after chemical modification can be evaluated by applying the Owens-Wendt approach (Owens and Wendt, 1969). According to the Owens-Wendt model, the adhesion work is assumed to verify the following equation:

$\mathrm{W}_{\mathrm{a}}=2 \sqrt{\mathrm{\gamma}_{\mathrm{S}}^{\mathrm{d}}} \sqrt{\mathrm{\gamma}_{\mathrm{L}}^{\mathrm{d}}}+2 \sqrt{\mathrm{\gamma}_{\mathrm{S}}^{\mathrm{p}}} \sqrt{\mathrm{\gamma}_{\mathrm{L}}^{\mathrm{p}}}$

where $\gamma_{L}{ }^{d}, \gamma_{L}{ }^{p}, \gamma_{S}{ }^{d}$ and $\gamma_{S}{ }^{p}$ are the dispersive and polar surface tension of the liquid and the solid, respectively. According to the Young-Dupré equation, the adhesion work is also given by:

$\mathrm{W}_{\mathrm{a}}=\mathrm{y}_{\mathrm{L}}(1+\cos \theta)$

Thereby,

$\gamma_{L}(1+\cos \theta)=2 \sqrt{\gamma_{S}^{d}} \sqrt{\gamma_{L}^{d}}+2 \sqrt{\gamma_{S}^{p}} \sqrt{\gamma_{L}^{p}}$

by plotting,

$\frac{\mathrm{y}_{\mathrm{L}}(1+\cos \theta)}{2 \sqrt{\mathrm{\gamma}_{\mathrm{L}}^{\mathrm{d}}}}=\mathrm{f}\left(\frac{\sqrt{\mathrm{y}_{\mathrm{L}}^{\mathrm{p}}}}{\sqrt{\mathrm{y}_{\mathrm{L}}^{\mathrm{d}}}}\right)$

$\sqrt{\gamma_{S}^{\mathrm{p}}}$ and $\sqrt{\gamma_{S}^{\mathrm{d}}}$ are deduced from the slope and the Y-axis point, respectively, of the straight line that is obtained. The surface energy of cellulose nanoparticles is given by the following equation:

$\gamma_{S}=y_{S}^{d}+y_{S}^{p}$

For the static angle values, at least three standard liquids of different polarity should be used, namely purely dispersive probes such as hexadecane and $\alpha$-bromonaphtalene and liquids with increasing polar character like diiodomethane, formamide and distilled water. Upon hydrophobization, the dispersive component of the surface energy of cellulose remains roughly constant while the polar component decreases (de Menezes et al., 2009). 


\subsubsection{Gravimetry}

The grafting efficiency can be determined by weighting the grafted cellulose nanoparticles (Habibi et al., 2008; Goffin et al., 2011b, Littunen et al., 2011) even if it is not strictly speaking an experimental technique. The following parameters were derived from gravimetric measurements for polymer-grafted cellulose nanoparticles using the "grafting onto" approach (Littunen et al., 2011):

$\begin{array}{ll}\text { Conversion } & =\frac{\mathrm{m}_{\mathrm{G}}+\mathrm{m}_{\mathrm{P}}}{\mathrm{m}_{\mathrm{M}}} \cdot 100 \% \\ \text { Graft yield } & =\frac{\mathrm{m}_{\mathrm{G}}}{\mathrm{m}_{\mathrm{C}}} \cdot 100 \% \\ \text { Graft efficiency } & =\frac{\mathrm{m}_{\mathrm{G}}}{\mathrm{m}_{\mathrm{G}}+\mathrm{m}_{\mathrm{P}}} \cdot 100 \% \\ \text { Polymer weight fraction } & =\frac{\mathrm{m}_{\mathrm{G}}}{\mathrm{m}_{\mathrm{G}}+\mathrm{m}_{\mathrm{C}}} \cdot 100 \%\end{array}$

where $\mathrm{m}_{\mathrm{G}}, \mathrm{m}_{\mathrm{P}}, \mathrm{m}_{\mathrm{M}}$ and $\mathrm{m}_{\mathrm{C}}$ correspond to the mass of the grafted polymer, homopolymer, fed monomer and cellulose, respectively. However, to apply this method one should ensures that the weight gain does not result from a solvent uptake when using a swelling solvent.

\subsubsection{Fourier transform infrared (FTIR) spectroscopy}

FTIR is a spectroscopic technique classically used to identify and study chemical compounds. It is based on how infrared radiation is absorbed by the compounds' chemical bonds. The mid-infrared, approximately $4000-400 \mathrm{~cm}^{-1}(2.5-25 \mu \mathrm{m})$, is used to study the fundamental vibrations and associated rotational-vibrational structure. A low amount of dried cellulose nanoparticles (typically $1 \mathrm{wt} \%$ ) is generally ground into a fine powder with $\mathrm{KBr}$ and pressed as pellets.

The FTIR spectrum of unmodified cellulose nanoparticles shows characteristic bands, viz. the hydrogen bonded $\mathrm{OH}$ stretching at ca. 4000-2995 $\mathrm{cm}^{-1}$, the CH stretching at $2900 \mathrm{~cm}^{-1}$, the $\mathrm{OH}$ bending of adsorbed water at $1635 \mathrm{~cm}^{-1}$, the $\mathrm{CH}_{2}$ bending at $1430 \mathrm{~cm}^{-1}$, the $\mathrm{CH}$ bending at $1380 \mathrm{~cm}^{-1}$, the $\mathrm{C}-\mathrm{O}$ stretching at 1058 and $1035 \mathrm{~cm}^{-1}$, the $\mathrm{CH}$ bending or $\mathrm{CH}_{2}$ stretching at $900 \mathrm{~cm}^{-1}$, which indicates the amorphous structure, e.g. in MFC, and the $\mathrm{OH}$ out-of-plane bending at $687 \mathrm{~cm}^{-1}$ (Klemm et al., 1998).

New bands are observed for chemically modified cellulose nanoparticles. The assignment of these new bands linked to the new functional groups introduced at the surface of the nanoparticles can be performed using an IR spectroscopy correlation table. 


\subsubsection{Elemental analysis}

Elemental analysis is used to quantify the mass fraction of carbon, hydrogen, oxygen and other atoms. It is based on atomic absorption of the investigated element. Compared to the pristine cellulose nanoparticle, the chemical modification changes the composition of the sample. The DS value can be obtained from this technique according to:

$\mathrm{DS}=\frac{6 \cdot \mathrm{Mc}-\mathrm{C} \cdot \mathrm{M}_{\mathrm{AGU}}}{\mathrm{M}_{\mathrm{g}} \cdot \mathrm{C}-\mathrm{M}_{\mathrm{Cg}}}$

where $C$ is the relative carbon content in the sample, and $6 \cdot \mathrm{Mc}, \mathrm{M}_{\mathrm{AGU}}, \mathrm{M}_{\mathrm{g}}$ and $\mathrm{M}_{\mathrm{Cg}}$ correspond to the carbon molecular weight of one anhydroglucose unit (72.07), mass of anhydroglucose unit (162.14), mass of the grafted molecule, and carbon mass of the grafted molecule, respectively.

\subsubsection{X-ray photoelectron spectroscopy (XPS)}

XPS is a powerful tool to investigate chemical changes resulting from surface modification. In XPS experiments, photons of a specific energy are used to excite the electronic states of atoms below the surface of the sample. Electrons ejected from the surface are energy-filtered before the intensity for a defined energy is recorded by a detector. Since core level electrons in solid-state atoms are quantified, the resulting energy spectra exhibit resonance peaks characteristic of the electronic structure for atoms at the sample surface. The escape depth of the ejected electrons is limited and ejected electrons from depths greater than $10 \mathrm{~nm}$ have a low probability of leaving the surface without undergoing an energy loss event, and therefore contribute to the background signal rather than well-defined photoelectric peaks. It therefore eliminates from the analysis the bulk of unmodified bulk material. Quantitative XPS analysis can be performed by calculating the atomic concentrations from the photoelectron peak areas using Gaussian -Lorentzian deconvolutions. Low resolution spectrum for cellulose shows that carbon and oxygen atoms are the main components. The corresponding peaks are observed around 287 and $534 \mathrm{eV}$, respectively. A small amount of sulfur is also detected when using $\mathrm{H}_{2} \mathrm{SO}_{4}$-hydrolysed nanocrystals.

The carbon 1s spectrum can be resolved into different contributions of bonded carbon which reflect their local environments, namely carbon without oxygen bonds $\mathrm{C} 1\left(\mathrm{C}-\mathrm{C}\right.$ and $\left.\mathrm{C}-\mathrm{H}_{\mathrm{x}}\right)$, carbon with one oxygen bond $\mathrm{C} 2(\mathrm{C}-\mathrm{O})$, carbon with two oxygen bonds $\mathrm{C} 3(\mathrm{O}-\mathrm{C}-\mathrm{O})$ and carbon with three oxygen bonds $\mathrm{C} 4(\mathrm{O}-\mathrm{C}=\mathrm{O})$. The carbonwithout-oxygen-bond contribution in the $\mathrm{C} 1 \mathrm{~s}$ emission is always set at $285.0 \mathrm{eV}$ (Watts and Wolstenholme, 2003). From the formula of pure cellulose (Figure 5.1), the theoretical $\mathrm{O} / \mathrm{C}$ ratio is $\mathrm{0.83}$, the contributions of $\mathrm{C} 1$ and $\mathrm{C} 4$ should be zero and the ratio 
of carbon atoms with two bonds to oxygen relative to carbon atoms with one bond to oxygen (C3/C2) should be 0.2. However, small amounts of $\mathrm{C}-\mathrm{C} / \mathrm{C}-\mathrm{H}_{\mathrm{x}}(\mathrm{C} 1)$ and $\mathrm{O}-$ $\mathrm{C}=\mathrm{O}(\mathrm{C} 4)$ carbon are always present in XPS spectra of pure cellulose nanoparticles although the cellulose molecule does not contain such carbon bonds. The presence of these non-cellulosic carbons has been explained by accumulation of air-borne contaminants and hemicelluloses (Johansson et al., 2011) as detailed in Section 5.2 of the present chapter.

After chemical modification, the proportions of carbon atoms involved in various chemical bonds are expected to change and new types of carbon bonds can appear depending on the grafted molecule. An example is given in Figure 5.16 that shows the deconvolution of the C1s peak for cellulose nanocrystals extracted from ramie fibers and chemically modified by grafting organic acid chlorides with different lengths of the aliphatic chain by an esterification reaction (de Menezes et al., 2008). The intensity of the $\mathrm{C} 1$ peak referring to aliphatic chains $(\mathrm{C}-\mathrm{H})$ considerably increased for modified samples compared to the pristine cellulose nanocrystals. The surface coverage by the alkane chains $\left(\theta_{\mathrm{SC}}\right)$ can be estimated from the $\mathrm{C} 1$ relative area according to:

$\theta_{\mathrm{SC}}=\mathrm{A}_{\mathrm{C} 1 \mathrm{~m}}-\mathrm{A}_{\mathrm{Clum}}$

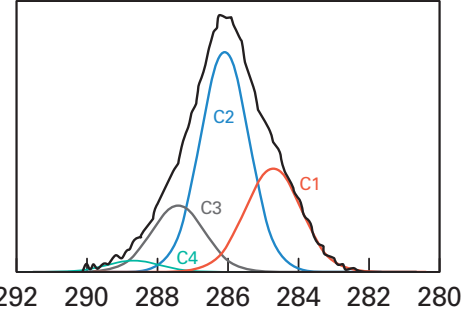

(a) binding energy $(\mathrm{eV}) \longrightarrow$

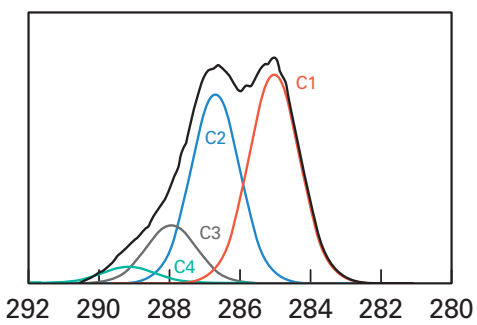

(c) binding energy $(\mathrm{eV})$

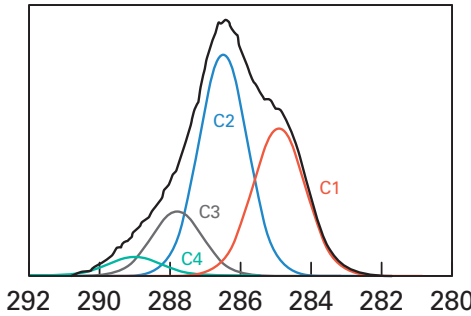

(b) binding energy $(\mathrm{eV}) \longrightarrow$

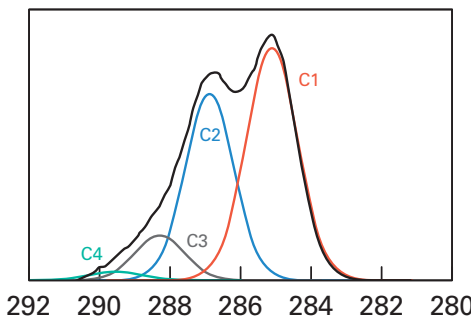

(d) binding energy $(\mathrm{eV}) \longrightarrow$

Fig. 5.16: Deconvolution of the C1S XPS signal into its constituent contributions ( $C 1$ : $C-C$ and $C-$ $\mathrm{H}_{\mathrm{x}}, \mathrm{C} 2: \mathrm{C}-\mathrm{O}, \mathrm{C} 3: \mathrm{O}-\mathrm{C}-\mathrm{O}$, and $\mathrm{C} 4: \mathrm{O}-\mathrm{C}=0$ ) for (a) unmodified ramie cellulose nanocrystals, and chemically modified with (b) hexanoyl chloride, (c) lauroyl chloride, and (d) stearoyl chloride (de Menezes et al., 2009). 
where $\mathrm{A}_{\mathrm{C} 1 \mathrm{~m}}$ and $\mathrm{A}_{\mathrm{Clum}}$ correspond to the areas for the modified and unmodified samples, respectively.

\subsubsection{Time of flight mass spectrometry (TOF-MS)}

TOF-MS is a surface-sensitive analytical method that uses a pulsed ion beam to remove molecules from the very outermost surface (atomic monolayers) of a sample. These ions are accelerated by an electric field. Ions with the same electric charge acquire the same kinetic energy but their velocity depends on the mass/charge ratio. This ratio determines the time (time of flight) taken by a charged molecule to reach a detector located at a known distance. Two ionization techniques are considered, viz. matrix-assisted laser desorption/ionization (MALDI-TOF-MS) and secondary ion mass spectrometry (TOF-SIMS).

MALDI-TOF-MS was used to show that PEO chains grafted onto the surface of cellulose nanocrystals had the same atomic mass units fragments than the starting polymer before grafting (Kloser and Gray, 2010). It was concluded that the PEO chains were covalently bonded to the nanocrystal surface. This technique was also used to determine the molecular weights of PAA chains grafted on cellulose nanocrystals (Majoinen et al., 2011).

\subsubsection{Solid-state NMR spectroscopy}

The solid state NMR spectrum of unmodified cellulose nanoparticles exhibits a pattern typical of native cellulose I with specific signals (Azzam et al., 2010). The region from 60 to 70 ppm is assigned to the hydroxymethyl C6 carbons, split in a 62-63 ppm contribution from the disordered chains mainly at the surface of the nanoparticles and $65 \mathrm{ppm}$ signal arising from the crystalline core. The region between 70 and $80 \mathrm{ppm}$ is attributed to C2, C3, and C5 carbons that are undistinguishable. The region from 80 to $91 \mathrm{ppm}$ is assigned to C4 carbons, where the wide signal at 83-84 ppm corresponds to the $\mathrm{C} 4$ carbons of disordered cellulose chains and the sharp signals at $88-89 \mathrm{ppm}$ to crystalline ones. The region around $105 \mathrm{ppm}$ is ascribed to $\mathrm{C} 1$ carbons. For oxidized cellulose nanoparticles, an additional signal around $174 \mathrm{ppm}$ characteristic of the carboxylic acid is observed (Montanari et al., 2005). Upon grafting, important changes occur in the NMR spectrum of cellulose nanoparticles and new resonances characteristic of the grafted species appear. According to the attribution and area of each signal, the DS of modified nanoparticles can be estimated by the ratio of corresponding areas. 


\subsubsection{Thermogravimetric analysis (TGA)}

Thermal stability is a crucial factor, especially when the cellulose nanoparticles are used as a reinforcement for polymers, because melt processing requires elevated temperatures. Compared to inorganic nanoparticles, many biomaterials suffer from inferior thermal stability. It is therefore important that alterations of the surface chemistry do not decrease the onset temperature of thermal degradation. TGA is typically performed by heating the sample from room temperature to $600-900^{\circ} \mathrm{C}$ at a given heating rate in a nitrogen, air or helium atmosphere.

TGA has been used to estimate the amount of PCL that was grafted on the surface of MFC (Lönnberg et al., 2008). Both MFC and free PCL displayed a monomodal shape derivative curve (DTGA) with only one maximum degradation rate temperature. On the contrary, the DTGA curves of PCL-grafted MFC had a bimodal shape with two different maxima and curve fitting was used to determine the sample composition. $\mathrm{H}_{2} \mathrm{SO}_{4}$-prepared cellulose nanocrystals display a reduced thermal stability because of the sulfate groups formed during the acid hydrolysis treatment. It was shown that their degradation temperature can be increased either by physical adsorption of macromolecules (Ben Azouz et al., 2012) or surface chemical grafting (Yi et al., 2009).

\subsubsection{Differential scanning calorimetry (DSC)}

Because of strong H-bonding interactions between cellulose chains, no thermal transition is observed before the degradation of the material. In some cases, a melting endotherm is observed for polymer-grafted cellulose nanoparticles (Habibi and Dufresne, 2008; Habibi et al., 2008; Lönnberg et al., 2008; Cao et al., 2009). It is attributed to the grafted polymeric chains that form a crystalline structure at the surface of the nanoparticles. Compared to the typical values of the melting point reported for the free polymer, the temperature position of this melting endotherm is lower because of the restricted size of these crystallites. As the molecular weight of the grafted chains increased, their melting temperature increased as shown for PCL-grafted MFC (Lönnberg et al., 2008). Because of the restricted mobility of grafted chains compared to free polymer chains, a lower degree of crystallinity and longer crystallization time were observed (Lönnberg et al., 2008).

\subsection{Conclusions}

Cellulose is inherently hydrophilic making it incompatible with organic liquid media and hydrophobic polymer matrices. However, the reactive hydroxyl groups of cellulose can be advantageously exploited to tune the surface properties of cellulose nanoparticles. Several strategies, including non-covalent and covalent bonding, 
have been proposed in the literature to hydrophobize these nanoparticles. It allows broadening the range of liquid media in which cellulose nanoparticles can be suspended and polymer matrices that can be used in association with them to process nanocomposite materials. Most of the studies reported on the surface chemical modification involve cellulose nanocrystals and covalent bonding. The common surface chemical modifications of cellulose nanocrystals are summarized in Figure 5.17 (Lin et al., 2012). They can be categorized into three distinctive groups, namely (1) substitution of hydroxyl groups with small molecules (as indicated with red arrows in Figure 5.17), (2) polymer grafting based on the "grafting onto" strategy with different coupling agents (as indicated with blue arrows in Figure 5.17), and (3) polymer

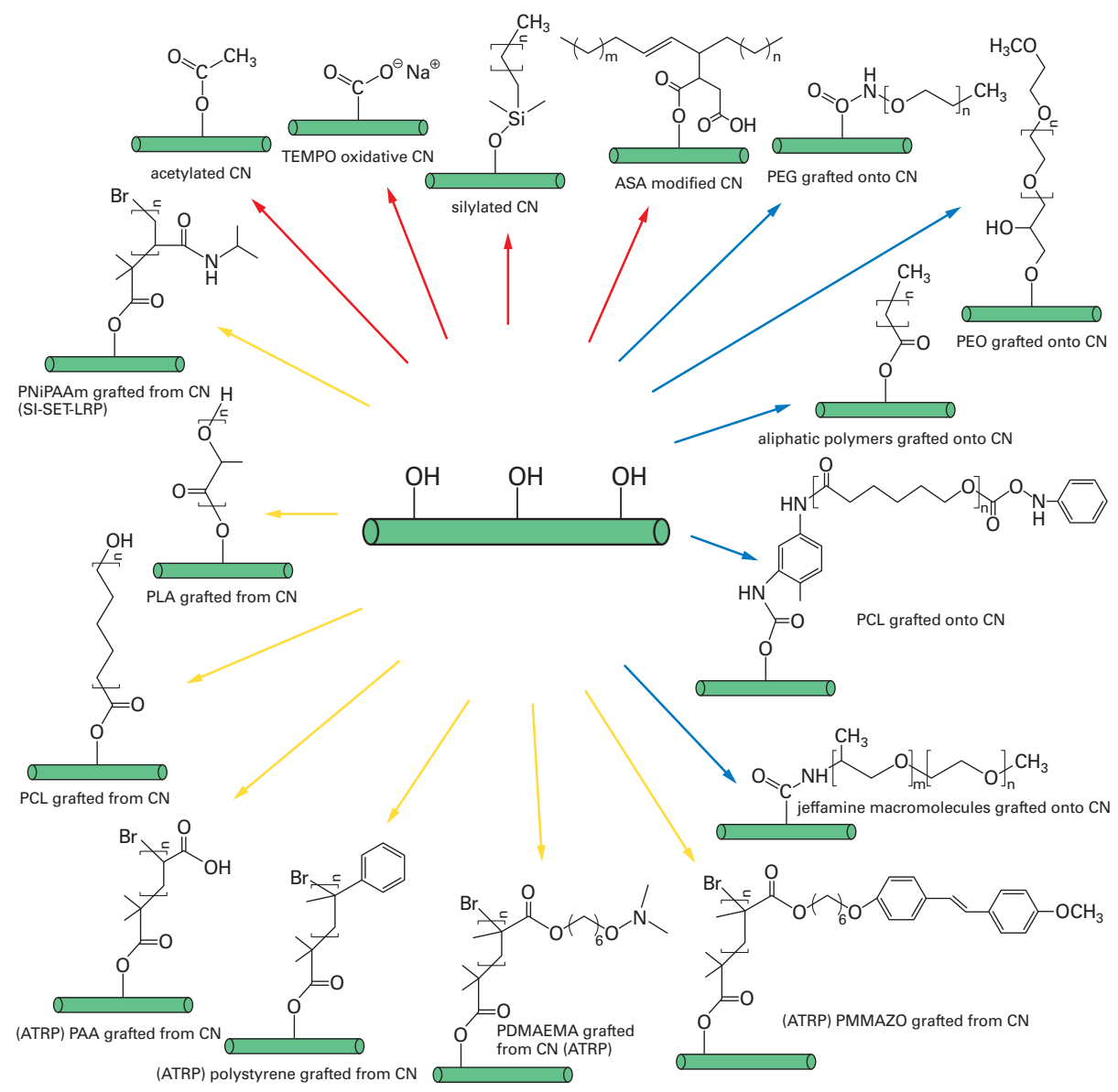

Fig. 5.17: Common surface covalent chemical modifications of cellulose nanocrystals. PEG: poly(ethylene glycol); PEO: poly(ethylene oxide); PLA: poly(lactic acid); PAA: poly(acrylic acid); PNiPAAm: poly( $N$-isopropylacrylamide); PDMAEMA: poly( $N, N$-dimethylaminoethyl methacrylate) (Lin et al., 2012). 
grafting based on the "grafting from" approach with a radical polymerization involving ring opening polymerization (ROP), atom transfer radical polymerization (ATRP) and single-electron transfer living radical polymerization (SET-LP) (as indicated with yellow arrows in Figure 5.17).

\subsection{References}

Andresen, M., Johansson, L.S., Tanem, B.S., and Stenius, P. (2006). Properties and characterization of hydrophobized microfibrillated cellulose. Cellulose 13, 665-677.

Andresen, M. and Stenius, P. (2007). Water-in-oil emulsions stabilized by hydrophobized microfibrillated cellulose. J. Disper. Science Technol. 28, 837-844.

Andresen, M., Stenstad, P., Møretrø, T., Langsrud, S., Syverud, K., Johansson, L.S. and Stenius, P. (2007). Nonleaching antimicrobial films prepared from surface-modified microfibrillated cellulose. Biomacromolecules 8, 2149-2155.

Angellier, H., Molina-Boisseau, S., Belgacem, M.N. and Dufresne, A. (2005). Surface chemical modification of waxy maize starch nanocrystals. Langmuir 21, 2425-2433.

Anglès, M.N. and Dufresne, A. (2000). Plasticized starch/tunicin whiskers nanocomposites. 1. Structural analysis. Macromolecules 33, 8344-8353.

Araki, J., Wada, M. and Kuga, S. (2001). Steric stabilization of a cellulose microcrystal suspension by poly(ethylene glycol) grafting. Langmuir 17, 21-27.

Aulin, C., Shchukarev, A., Lindqvist, J., Malmström, E., Wågberg, L. and Lindström, T. (2008). Wetting kinetics of oil mixtures on fluorinated model cellulose surfaces. J. Colloid Interface Sci. 317, 556-567.

Aulin, C. Ahola, S., Josefsson, P., Nishino, T., Hirose, Y., Österberg, M. and Wågberg, L. (2009). Nanoscale cellulose films with different crystallinities and mesostructures - Their surface properties and interaction with water. Langmuir 25, 7675-7685.

Azzam, F., Heux, L., Putaux, J.L. and Jean, B. (2010). Preparation by grafting onto, characterization, and properties of thermally responsive polymer-decorated cellulose nanocrystals. Biomacromolecules 11, 3652-3659.

Barazzouk, S. and Daneault, C. (2011). Spectroscopic characterization of oxidized nanocellulose grafted with fluorescent amino acids. Cellulose 18, 643-653.

Ben Azouz, K., Ramires, E.C., Van den Fonteyne, W., El Kissi, N. and Dufresne A. (2012). A simple method for the melt extrusion of cellulose nanocrystal reinforced hydrophobic polymer. ACS Macro Lett. 1, 236-240.

Bergenstråhle, M., Mazeau, K. and Berglund, L.A. (2008). Molecular modeling of interfaces between cellulose crystals and surrounding molecules: Effects of caprolactone surface grafting. Eur. Polym. J. 44, 3662-3669.

Berlioz, S., Molina-Boisseau, S., Nishiyama, Y. and Heux, L. (2009). Gas-phase surface esterification of cellulose microfibrils and whiskers. Biomacromolecules 10, 2144-2151.

Besbes, I., Alila, S. and Boufi, S. (2011a). Nanofibrillated cellulose from TEMPO-oxidized eucalyptus fibres: Effect of the carboxyl content. Carbohydr. Polym. 84, 975-983.

Besbes, I., Rei Vilar, M. and Boufi, S. (2011b). Nanofibrillated cellulose from alfa, eucalyptus and pine fibres: preparation, characteristics and reinforcing potential. Carbohydr. Polym. 86, 1198-1206.

Bondeson, D. and Oksman, K. (2007). Dispersion and characteristics of surfactant modified cellulose whiskers nanocomposites. Compos. Interfaces 14, 617-630. 
Bonini, C., Heux, L. Cavaillé, J.Y., Lindner, P., Dewhurst, C. and Terech, P. (2002). Rodlike cellulose whiskers coated with surfactant: A small-angle neutron scattering characterization. Langmuir 18, 3311-3314.

Braun, B. and Dorgan, J.R. (2009). Single-step method for the isolation and surface functionalization of cellulosic nanowhiskers. Biomacromolecules 10, 334-341.

Cao, X., Habibi, Y. and Lucia, L.A. (2009). One-pot polymerization, surface grafting, and processing of waterborne polyurethane-cellulose nanocrystal nanocomposites. J. Mater. Chem. 19, 7137-7145.

Cateto, C.A. and Ragauskas, A. (2011). Amino acid modified cellulose whiskers. RSC Advances 1, 1695-1697.

Çetin, N.S., Tingaut, P., Ozmen, N., Henry, N., Harper, D., Dadmun, M. and Sebe, G. (2009). Acetylation of cellulose nanowhiskers with vinyl acetate under moderate conditions. Macromol. Biosci. 9, 997-1003.

Dankovich, T.A. and Gray, D.G. (2011). Contact angle measurements on smooth nanocrystalline cellulose (I) thin films, J. Adhesion Sci. Technol. 25, 699-708.

de Menezes, A.J., Siqueira, G., Curvelo, A.A.S. and Dufresne, A. (2009). Extrusion and characterization of functionalized cellulose whisker reinforced polyethylene nanocomposites. Polymer 50, 4552-4563.

De Nooy, A.E.J., Besemer, A.C. and Van Bekkum, H. (1995). Highly selective nitroxyl radical-mediated oxidation of primary alcohol groups in water-soluble glucans. Carbohydr. Res. 269, 89-98.

Dong, S. and Roman, M. (2007). Fluorescently labeled cellulose nanocrystals for bioimaging applications. J. Am. Chem. Soc. 129, 13810-13811.

Dufresne, A. (2010). Processing of polymer nanocomposites reinforced with polysaccharide nanocrystals. Molecules 15, 4111-4128.

Elazzouzi-Hafraoui, S., Putaux, J.L. and Heux, L. (2009). Self-assembling and chiral nematic properties of organophilic cellulose nanocrystals. J. Phys. Chem. B 113, 11069-11075.

Eriksson, M., Notley, S.M. and Wågberg, L. (2007). Cellulose thin films: Degree of cellulose ordering and its influence on adhesion. Biomacromolecules 8, 912-919.

Eyholzer, C., Bordeanu, N., Lopez-Suevos, F., Rentsch, D., Zimmermann, T. and Oksman, K. (2010). Preparation and characterization of water-redispersible nanofibrillated cellulose in powder form. Cellulose, 17, 19-30.

Eyley, S. and Thielemans, W. (2011). Imidazolium grafted cellulose nanocrystals for ion exchange applications. Chem. Comm. 47, 4177-4179.

Favier, V., Canova, G.R., Shrivastava, S.C. and Cavaillé, J.Y. (1997). Mechanical percolation in cellulose whiskers nanocomposites. Polym. Eng. Sci. 37, 1732-1739.

Filpponen, I. and Argyropoulos, D.S. (2010). Regular linking of cellulose nanocrystals via click chemistry: Synthesis and formation of cellulose nanoplatelet gels. Biomacromolecules 11, 1060-1066.

Follain, N., Marais, M.F., Montanari, S. and Vignon, M.R. (2010). Coupling onto surface carboxylated cellulose nanocrystals. Polymer 51, 5332-5344.

Fortunati, E., Armentano, I., Zhou, Q., Iannoni, A., Saino, E., Visai, L., Berglund, L.A. and Kenny, J.M. (2012). Multifunctional bionanocomposite films of poly(lactic acid), cellulose nanocrystals and silver nanoparticles. Carbohydr. Polym. 87, 1596-1605.

Gardner, K.H. and Blackwell, J. (1974). The structure of native cellulose. Biopolymers 13, 1975-2001.

Goffin, A.-L. (2010). Polymer bionanocomposites reinforced by functionalized nanoparticles: Impact of nanofiller size, nature and composition. PhD Thesis, Mons University, Belgium.

Goffin, A.-L., Raquez, J.-M., Duquesne, E., Siqueira, G., Habibi, Y., Dufresne, A. and Dubois, Ph. (2011a). Poly(e-caprolactone) based nanocomposites reinforced by surface-grafted cellulose nanowhiskers via extrusion processing: Morphology, rheology, and thermo-mechanical properties. Polymer 52, 1532-1538. 
Goffin, A.-L., Raquez, J.-M., Duquesne, E., Siqueira, G., Habibi, Y., Dufresne, A. and Dubois, $\mathrm{Ph}$. (2011b). From interfacial ring-opening polymerization to melt processing of cellulose nanowhisker-filled polylactide-based nanocomposites. Biomacromolecules 12, 2456-2465.

Gopalan Nair, K., Dufresne, A., Gandini, A. and Belgacem, M.N. (2003). Crab shell chitin whiskers reinforced natural rubber nanocomposites. 3. Effect of chemical modification of chitin whiskers. Biomacromolecules 4, 1835-1842.

Goussé, C., Chanzy, H., Excoffier, G., Soubeyrand, L. and Fleury, E. (2002). Stable suspensions of partially silylated cellulose whiskers dispersed in organic solvents. Polymer 43, 2645-2651.

Goussé, C., Chanzy, H., Cerrada, M.L. and Fleury, E. (2004). Surface silylation of cellulose microfibrils: Preparation and rheological properties. Polymer 45, 1569-1575.

Grunert, M. and Winter, W. T. (2002a). Nanocomposites of cellulose acetate butyrate reinforced with cellulose nanocrystals. J. Polym. Envir. 10, 27-30.

Grunert, M. and Winter, W. T. (2002b). Cellulose nanocrystal reinforced acetate butyrate nanocomposites. Polym. Mater. Sci. Eng. 86, 367-368.

Habibi, Y., Chanzy, H. and Vignon, M.R. (2006). TEMPO-mediated surface oxidation of cellulose whiskers. Cellulose 13, 679-687.

Habibi, Y. and Dufresne, A. (2008). Highly filled bionanocomposites from functionalized polysaccharide nanocrystals. Biomacromolecules 9, 1974-1980.

Habibi, Y., Goffin, A.L., Schiltz, N., Duquesne, E., Dubois, P. and Dufresne A. (2008). Bionanocomposites based on poly( $\varepsilon$-caprolactone)-grafted cellulose nanocrystals by ring opening polymerization. J. Mat. Chem. 18, 5002-5010.

Habibi, Y., Hoegert, I., Kelley, S.S., and Rojas, O.J. (2010). Development of Langmuir-Schaeffer cellulose nanocrystal monolayers and their interfacial behaviours. Langmuir 26, 990-1001.

Harrisson, S., Drisko, G.L., Malmström, E., Hult, A. and Wooley, K.L. (2011). Hybrid rigid/ soft and biologic/synthetic materials: Polymers grafted onto cellulose microcrystals. Biomacromolecules 12, 1214-1223.

Hasani, M., Cranston, E.D., Westman, G. and Gray, D.G. (2008). Cationic surface functionalisation of cellulose nanocrystals. Soft Matter 4, 2238-2244.

Hebeish, A. and Guthrie, J.T. (1981). The chemistry and technology of cellulosic copolymers (Springer-Verlag, Berlin).

Helbert, W., Cavaillé, J.Y. and Dufresne, A. (1996). Thermoplastic nanocomposites filled with wheat straw cellulose whiskers. Part I: Processing and mechanical behavior. Polym. Comp. 17, 604-611.

Heux, L., Chauve, G. and Bonini, C. (2000). Nonflocculating and chiral-nematic self-ordering of cellulose microcrystals suspensions in nonpolar solvents. Langmuir 16, 8210-8212.

Ifuku, S., Nogi, M., Abe, K., Handa, K., Nakatsubo, F. and Yano, H. (2007). Surface modification of bacterial cellulose nanofibers for property enhancement of optically transparent composites: Dependence on acetyl-group DS. Biomacromolecules 8, 1973-1978.

Isogai, A., Saito, T. and Fukuzumi, H. (2011). TEMPO-oxidized cellulose nanofibers. Nanoscale 3 , 71-85.

Johansson, L.S., Tammelin, T., Campbell, J.M., Setälä, H. and Österberg, M. (2011). Experimental evidence on medium driven cellulose surface adaptation demonstrated using nanofibrillated cellulose. Soft Matter 7, 10917-10924.

Jonoobi, M., Harun, J., Mathew, A.P., Hussein, M.Z.B. and Oksman, K. (2010). Preparation of cellulose nanofibers with hydrophobic surface characteristics. Cellulose 17, 299-307.

Kim, J., Montero, G. Habibi, Y., Hinestroza, J.P., Genzer, J., Argyropoulos, D.S. and Rojas, O.J. (2009). Dispersion of cellulose crystallites by nonionic surfactants in a hydrophobic polymer matrix. Polym. Eng. Sci. 49, 2054-2061. 
Klemm, D., Philipp, B., Heinze, T. Heinze, U., and Wagenknecht, W. (1998). Comprehensive cellulose chemistry. Vol. 1: Fundamentals and analytical methods (Wiley-VCH Verlag GmbH \& Co, Weinheim, Germany).

Kloser, E. and Gray, D.G. (2010). Surface grafting of cellulose nanocrystals with poly(ethylene oxide) in aqueous media. Langmuir 26, 13450-13456.

Kowalski, A., Libiszowski, J., Biela, T., Cypryk, M., Duda, A. and Penczek, S. (2005). Kinetics and mechanism of cyclic esters polymerization initiated with Tin(II) octoate. Polymerization of e-caprolactone and L,L-lactide co-initiated with primary amines. Macromolecules 38 , 8170-8176.

Krassig, H.A. (1985). Structure of cellulose and its relation to properties of cellulose fibers. In: Cellulose and its derivatives: Chemistry, biochemistry and applications, J.F. Kennedy, G.O. Phillips, D.J. Wedlock and P.A. Williams, eds. (Ellis Horwood Limited, Chichester, UK), pp. 3-25.

Krassig, H.A. (1993). Cellulose-structure, accessibility and reactivity (Gordon and Breach Science Publisher, Yverdon, Switzerland).

Kvien, I., Tanem, B.S. and Oksman, K. (2005). Characterization of cellulose whiskers and their nanocomposites by atomic force and electron microscopy. Biomacromolecules 6, 3160-3165.

Labet, M., Thielemans, W. and Dufresne A. (2007). Polymer grafting onto starch nanocrystals. Biomacromolecules 8, 2916-2927.

Labet, M. and Thielemans, W. (2011). Improving the reproducibility of chemical reactions on the surface of cellulose nanocrystals: ROP of e-caprolactone as a case study. Cellulose 18, 607-617.

Lee, K.Y., Quero, F., Blaker, J.J., Hill, C.A.S., Eichhorn, S.J. and Bismarck, A. (2011). Surface only modification of bacterial cellulose nanofibres with organic acids. Cellulose 18, 595-605.

Lin, N., Chen, G., Huang, J., Dufresne, A. and Chang, P.R. (2009). Effects of polymer-grafted natural nanocrystals on the structure and mechanical properties of poly(lactic acid): a case of cellulose whisker-graft-polycaprolactone. J. Appl. Polym. Sci. 113, 3417-3425.

Lin, N., Huang, J., Chang, P.R., Feng, J. and Yu, J. (2011). Surface acetylation of cellulose nanocrystal and its reinforcing function in poly(lactic acid). Carbohydr. Polym. 83, 1834-1842.

Lin, N., Huang, J. and Dufresne A. (2012). Preparations, properties and applications of polysaccharide nanocrystals in advanced functional nanomaterials: A review. Nanoscale 4, 3274-3294.

Littunen, K., Hippi, U., Johansson, L.S., Österberg, M., Tammelin, T., Laine, J. and Seppälä, J. (2011). Free radical graft polymerization of nanofibrillated cellulose with acrylic monomers. Carbohydr. Polym. 84, 1039-1047.

Lönnberg, H., Fogelström, L., Azizi Samir, M.A.S., Berglund, L., Malmström, E. and Hult, A. (2008). Surface grafting of microfibrillated cellulose with poly(e-caprolactone) - Synthesis and characterization. Eur. Polym. J. 44, 2991-2997.

Lu, J., Askeland, P. and Drzal, L.T. (2008). Surface modification of microfibrillated cellulose for epoxy composite applications. Polymer 49, 1285-1296.

Mahmoud, K.A., Mena, J.A., Male, K.B., Hrapovic, S., Kamen, A. and Luong, J.H.T. (2010). Effect of surface charge on the cellular uptake and cytotoxicity of fluorescent labeled cellulose nanocrystals. ACS Appl. Mater. Interfaces 2, 2924-2932.

Majoinen, J., Walther, A., McKee, J.R., Kontturi, E., Aseyev, V., Malho, J.M., Ruokolainen, J. and Ikkala, O. (2011). Polyelectrolyte brushes grafted from cellulose nanocrystals using Cu-mediated surface-initiated controlled radical polymerization. Biomacromolecules 12, 2997-3006.

Mangalam, A.P., Simonsen, J. and Benight, A.S. (2009). Cellulose/DNA hybrid nanomaterials. Biomacromolecules 10, 497-504.

Montanari, S., Roumani, M., Heux, L. and Vignon, M.R. (2005). Topochemistry of carboxymethylated nanocrystals resulting from TEMPO-mediated oxidation. Macromolecules 38, 1665-1671.

Moon, R.J., Martini, A., Nairn, J., Simonsen, J. and Youngblood, J. (2011). Cellulose nanomaterials review: Structure, properties and nanocomposites. Chem. Soc. Rev. 40, 3941-3994. 
Morandi, G., Heath, L. and Thielemans, W. (2009). Cellulose nanocrystals grafted with polystyrene chains through surface-initiated atom transfer radical polymerization (SI-ATRP). Langmuir 25, $8280-8286$.

Nielsen, L.J., Eyley, S., Thielemans, W. and Aylott, J.W. (2010). Dual fluorescent labelling of cellulose nanocrystals for pH sensing. Chem. Commun. 46, 8929-8931.

Nogi, M., Abe, K., Handa, K., Nakatsubo, F., Ifuku, S. and Yano, H. (2006). Property enhancement of optically transparent bionanofiber composites by acetylation. Appl. Phys. Lett. 89, 233123-1233123-3.

Owens, D.K. and Wendt, R.C. (1969). Estimation of the surface free energy of polymers. J. Appl. Polym. Sci. 13, 1741-1747.

Pei, A., Zhou, Q. and Berglund, L. (2010). Functionalized cellulose nanocrystals as biobased nucleation agents in poly(L-lactide) (PLLA) - Crystallization and mechanical property effects. Compos. Sci. Technol. 70, 815-821.

Raquez, J.M., Murena, Y., Goffin, A.L., Habibi, Y., Ruelle, B., DeBuyl, F. and Dubois, P. (2012). Surfacemodification of cellulose nanowhiskers and their use as nanoreinforcers into polylactide: $A$ sustainably-integrated approach. Compos. Sci. Technol. 72, 544-549.

Rodionova, G., Lenes, M., Eriksen, $\varnothing$. and Gregersen, $\varnothing$. (2011). Surface chemical modification of microfibrillated cellulose: Improvement of barrier properties for packaging applications. Cellulose 18, 127-134.

Rojas, O.J., Montero, G.A. and Habibi, Y. (2009). Electrospun nanocomposites from polystyrene loaded with cellulose nanowhiskers. J. Appl. Polym. Sci. 113, 927-935.

Roy, D., Semsarilar, M., Guthrie, J.T. and Perrier, S. (2009). Cellulose modification by polymer grafting: A review. Chem. Soc. Rev. 38, 2046-2064.

Saito, T. and Isogai, A. (2004). TEMPO-mediated oxidation of native cellulose. The effect of oxidation conditions on chemical and crystal structures of the water-insoluble fractions. Biomacromolecules 5, 1983-1989.

Saito, T. and Isogai, A. (2006). Introduction of aldehyde groups on surfaces of native cellulose fibers by TEMPO-mediated oxidation. Colloid Surface A 289, 219-225.

Saito, T., Hirota, M., Tamura, N., Kimura, S., Fukuzumi, H., Heux, L. and Isogai, A. (2009). Individualization of nano-sized plant cellulose fibrils by direct surface carboxylation using TEMPO catalyst under neutral conditions. Biomacromolecules 10, 1992-1996.

Sassi, J.F. and Chanzy, H. (1995). Ultrastructural aspects of the acetylation of cellulose. Cellulose 2, 111-127.

Shibata, I. and Isogai, A. (2003). Depolymerization of cellouronic acid during TEMPO-mediated oxidation. Cellulose 10, 151-158.

Siqueira, G., Bras, J. and Dufresne, A. (2009). New process of chemical grafting of cellulose nanoparticles with a long chain isocyanate. Langmuir 26, 402-411.

Sobkowicz, M.J., Braun, B. and Dorgan, J.R. (2009). Decorating in green: Surface esterification of carbon and cellulosic nanoparticles. Green Chem. 11, 680-682.

Stenstad, P., Andresen, M., Tanem, B.S. and Stenius, P. (2008). Chemical surface modifications of microfibrillated cellulose. Cellulose 15, 35-45.

Storey, R.F. and Sherman, J.W. (2002). Kinetics and mechanism of the stannous octoate-catalyzed bulk polymerization of e-caprolactone. Macromolecules 35, 1504-1512.

Syverud, K., Xhanari, K., Chinga-Carrasco, G., Yu, Y. and Stenius, P. (2011). Films made of cellulose nanofibrils: surface modification by adsorption of a cationic surfactant and characterization by computer-assisted electron microscopy J. Nanoparticle Res. 13, 773-782.

Tingaut, P., Zimmermann, T. and Lopez-Suevos, F. (2010). Synthesis and characterization of bionanocomposites with tunable properties from poly(lactic acid) and acetylated microfibrillated cellulose. Biomacromolecules 11, 454-464. 
Trejo-O'Reilly, J.A., Cavaillé, J.Y. and Gandini, A. (1997). The surface chemical modification of cellulosic fibres in view of their use in composite materials. Cellulose 4, 305-320.

Wågberg, L., Decher, G., Norgren, M., Lindström, T., Ankerfors, M. and Axnäs, K. (2008). The build-up of polyelectrolyte multilayers of microfibrillated cellulose and cationic polyelectrolytes. Langmuir 24, 784-795.

Wakelyn, P.J. (1998). Chemical properties of cotton. In: Handbook of fiber chemistry, M. Levin and E.M. Pearce, eds. (Marcel Dekker, New York), pp. 642-654.

Wang, N., Ding, E. and Cheng, R. (2007). Surface modification of cellulose nanocrystals. Front. Chem. Eng. China 1, 228-232.

Watts, J.F. and Wolstenholme, J. (2003). An introduction to surface analysis by XPS and AES (John Wiley \& Sons Ltd, Chichester).

Xhanari, K., Syverud, K., Chinga-Carrasco, G., Paso, K. and Stenius, P. (2011). Reduction of water wettability of nanofibrillated cellulose by adsorption of cationic surfactants. Cellulose 18 , 257-270.

Xu, Q., Yi, J., Zhang, X. and Zhang, H. (2008). A novel amphotropic polymer based on cellulose nanocrystals grafted with azo polymers. Eur. Polym. J. 44, 2830-2837.

Yi, J., Xu, Q., Zhang, X. and Zhang, H. (2008). Chiral-nematic self-ordering of rodlike cellulose nanocrystals grafted with poly(styrene) in both thermotropic and lyotropic states. Polymer 49 , 4406-4412.

Yi, J., Xu, Q., Zhang, X. and Zhang, H. (2009). Temperature-induced chiral nematic changes of suspensions of poly(N,N-dimethylaminoethyl methacrylate)-grafted cellulose nanocrystals. Cellulose 16, 989-997.

Yuan, H., Nishiyama, Y., Wada, M. and Kuga, S. (2006). Surface acylation of cellulose whiskers by drying aqueous emulsion. Biomacromolecules 7, 696-700.

Zhou, Q., Brumer, H. and Teeri, T.T. (2009). Self-organization of cellulose nanocrystals adsorbed with xyloglucan oligosaccharide-poly(ethylene glycol)-polystyrene triblock copolymer. Macromolecules 42, 5430-5432.

Zoppe, J.O., Peresin, M.S., Habibi, Y., Venditti, R.A. and Rojas, O.J. (2009). Reinforcing poly(ecaprolactone) nanofibers with cellulose nanocrystals. ACS Appl. Mat. Interfaces 1, 1996-2004.

Zoppe, J.O., Habibi, Y., Rojas, O.J., Venditti, R.A., Johansson, L.S., Efimenko, K., Österberg, M. and Laine, J. (2010). Poly(N-isopropylacrylamide) brushes grafted from cellulose nanocrystals via surface-initiated single-electron transfer living radical polymerization. Biomacromolecules 11 , 2683-2691. 
